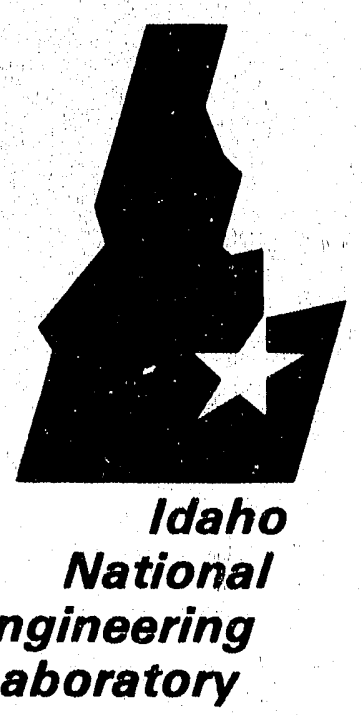

Managed by the U.S. Department of Energy
EGG-GEO-10068

January 1992

A MODELING STUDY OF WATER FLOW IN THE VADOSE ZONE BENEATH THE RADIOACTIVE WASTE MANAGEMENT COMPLEX

Robert G. Baca

Swen O. Magnuson

Hoa D. Nguyen

Pete Martian

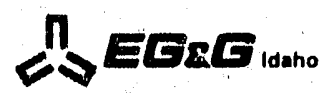

Work performed under DOE Contract No. DE-AC07-761D01570 
This document contains new concepts or the author(s) interpretation of new calculations and/or measurements; accordingly, EG\&G Idaho, Inc. is required by the United States Government to include the following disclaimer:

\section{DISCLAIMER}

This report was prepared as an account of work sponsored by an agency of the United States Government. Neither the United States Government nor any agency thereot, nor any of their employees, makes any warranty, express or implied, or assumes any legal liability or responsibility for the accuracy, completeness, or usefulness of any information, apparatus, product or process disclosed, or represents that its use would not infringe privately owned rights. References herein to any specific commercial product, process, or service by trade name, trademark, manulacturer, or otherwise, does not necessarily constitute or imply its endorsement, recommendation, or favoring by the United States Government or any agency thereot. The views and opinions of authors expressed herein do not necessarily state or reflect those of the United States Government or any agency thereof. 
EGG-GEO--10068

DE92 012320

\title{
A MODELING STUDY OF WATER FLOW IN THE VADOSE ZONE BENEATH THE RADIOACTIVE WASTE MANAGEMENT COMPLEX
}

\author{
Ro'sert G. Baca \\ Swen O. Magnuson \\ Hoa D. Nguyen \\ Pete Martian \\ Subsurface and Environmental Modeling Unit \\ Geosciences Group
}

January 1992

Idaho National Engineering Laboratory

EG\&G Idaho, Inc.

P. O. Box 1625

Idaho Falls, Idaho 83415

Prepared for the

U. S. Department of Energy

Office of Environmental Restoration and Waste Management

Under DOE Idaho Field Office Contract No. DE-AC07-76!DO1570 


\begin{abstract}
A modeling study was conducted for the purpose of gaining insight into the nature of water flow in the vadose zone beneath the Radioactive Waste Management Complex (RWMC). The modeling study focused on three specific hydrologic aspects: (1) relationship between meteorologic conditions and net infiltration, (2) water movement associated with past flooding events, and (3) estimation of water travel-times through the vadose zone. This information is necessary for understanding how contaminants may be transported through the vadose zone.

Evaluations of net infiltration at the RWMC were performed by modeling the processes of precipitation, evaporation, infiltration and soil-moisture redistribution. Water flow simulations were performed for two distinct time periods, namely 1955-1964 and 1984-1990. The patterns of infiltration were calculated for both the undisturbed (or natural sediments) and the pit/trench cover materials. Water balance calculations suggest that $10 \mathrm{~cm} / \mathrm{yr}$ or greater would be a conservative bound for the average annual infiltration rate.

Detailed simulations of the 1969 flooding of Pit 10 were performed to estimate the rate and extent of water movement through the vadose zone. The simulation results indicate that this event alone may have moved a significant volume of water through the vadose zone in a relatively short time. It is estimated that the flooding front may have reached the $110 \mathrm{ft}$ interbed within as little as 1 month time.

Water travel-times through the vadose zone were estimated using a Monte Carlo simulation approach. The simulations accounted for variability of soil and rock hydraulic properties as well as variations in the infiltration rate. The statistical distribution of water travel-time exhibits a log-normal trend with a geometric mean travel-time of 610 yrs.

The information presented in this report will be used in future performance assessments of the RWMC site. Future assessment are expected to be conducted to: (1) evaluate compliance with requirements in DOE Order 5820.2A, (2) compare alternatives for final disposition of the wastes and (3) support studies associated with the CERCLA and RCRA Remedial Investigation/Feasibility (RI/FS) process.
\end{abstract}


Page

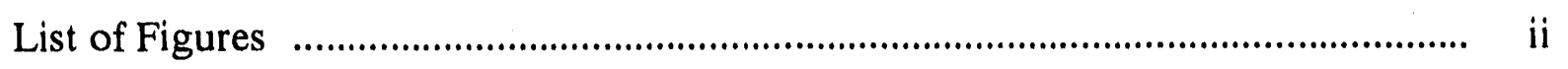

List of Tables ................................................................................................. iii

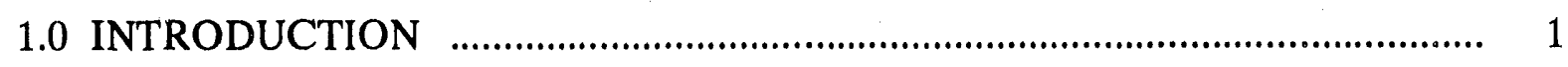

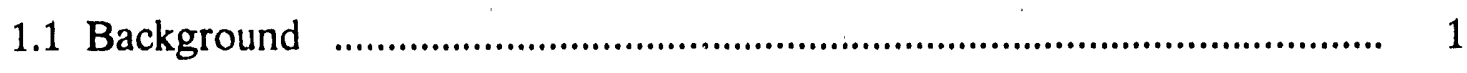

1.2 Performance Assessment Issues ................................................................. 2

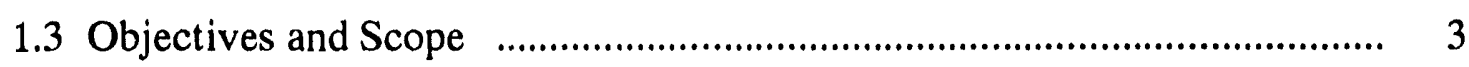

2.0 PHYSICAL SETTING _....................................................................... 5

2.1 Description of the Model Study Area ………….......................................... 5

2.2 Hydraulic Properties ................................................................................. 8

2.3 Climatic Conditions .............................................................................. 9

3.0 MODELING APPROACHES …............................................................ 10

3.1 Conceptual Framework and Assumptions ……......................................... 10

3.2 Fluid Flow Equation and Boundary Conditions ….................................... 11

3.3 Description of the Computer Codes ………............................................... 12

4.0 WATER FLOW THROUGH SURFICIAL SEDIMENTS _................................ 13

4.1 Description of Model Study Area ………............................................. 13

4.2 Parameterization of Hydraulic Properties .................................................. 14

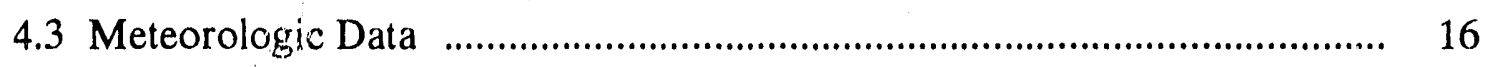

4.4 Simulations of Pore-Water Movement …………................................... 18

5.0 WATER FLOW FROM FLOODING EVENTS .............................................. 22

5.1 Introduction ........................................................................................ 22

5.2. Parameterization of Hydraulic Properties ................................................. 22

5.3 Initial and Boundary Conditions ……................................................... 25

5.4 Simulations of Wetting Front Advance …………....................................... 27

6.0 WATER TRAVT:-TIME PREDICTIONS ………....................................... 34

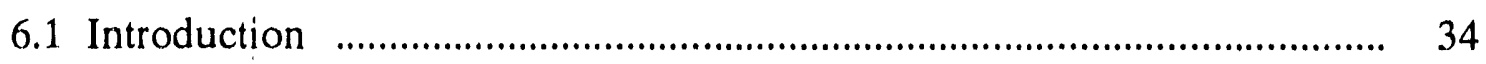

6.2 Parameterization of Hydraulic Properties …………............................. 35

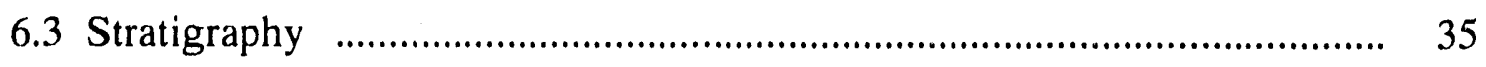

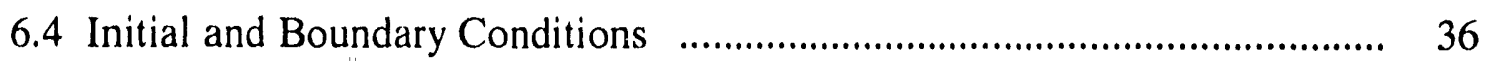

6.5 Statistical Distribution of Water Travel-Times f......................................... $\quad 36$ 


\section{Table of Contents (Continued)}

7.0 PRELIMINARY FINDINGS AND RECOMMENDATIONS

7.1 Analysis of Infiltration Rates

7.2 Evaluation of Pit 10 Flooding ……….................................................. 42

7.3 Estimation of Water Travel-Times ……………....................................... 43

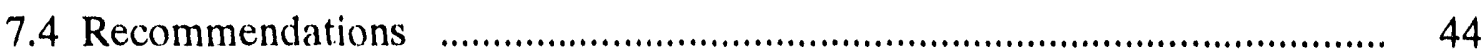

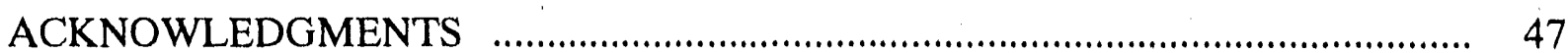

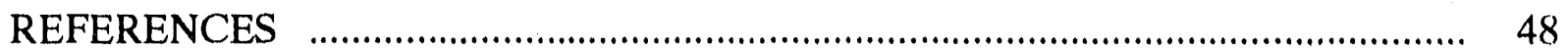

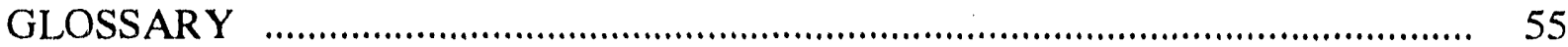

APPENDIX I - DESCRIPTION OF COMPUTER CODES …................................. 59

APPENDIX II - HYDRAULIC DATA FOR MONTE CARLO SIMULATIONS $\ldots .67$

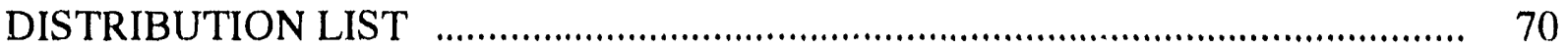

\section{List of Figures}

1 Location of the Radioactive Waste Management Complex …………............. 6

2 Cross-sections for Surficial Sediments and Basalt ....................................... 13

$3 \quad$ Characteristic and Conductivity Curves for Sediments and Basalt ................. 15

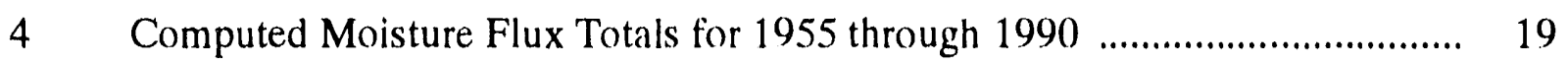

$5 \quad$ Daily Moisture Fluxes for Soil Surface and $50 \mathrm{~cm}$ depth ................................ 20

$6 \quad$ Daily Moisture Fluxes for 150 and $350 \mathrm{~cm}$ depth ......................................... 21

$7 \quad$ Characteristic and Conductivity Curves for the Vadose Zone .......................... 23

8 Initial Conditions for Pit 10 Simulation …………......................................... 26

$9 \quad$ Base Case - Pressure Heads at 4 and 20 days ............................................... 28

$10 \quad$ Base Case - Pressure Heads at 25 and 45 days .............................................. 29

11 Fractured Case - Pressure Heads at 4 and 20 days ......................................... 31

12 Fractured Case - Pressure Heads at 25 and 45 days ....................................... 32

13 Conductivity and Pressure Profiles for a Random Trial .................................. 37

14 Vadose Zone Water Travel-Time Histogram ............................................... 38

15 Cumulative Distribution Function for Water Travel-Times ............................. 40 


\section{Table of Contents (Continued)}

List of Tables Page

$1 \quad$ Thicknesses of Individual Basalt Flow Elements .............................................. 7

2 van Genuchten Parameters for Sediments and Basalt ..................................... 16

3 van Genuchten Parameters for Vadose Zone .................................................. 24

$4 \quad$ Convergence of Travel-Time Mean and Standard Deviation ........................... 39 


\subsection{INTRODUCTION}

\subsection{BACKGROUND}

Since the mid-1950's, the Radioactive Waste Management Complex (RWMC), located in the southwestern portion of the Idaho National Engineering Laboratory (INEL), has been used for storage and disposal of wastes generated by national defense programs and reactor research activities. Transuranic and low-level radioactive wastes mixed with hazardous constituents have been disposed in the Subsurface Disposal Area (SDA) of the RWMC. Over the past ten years, significant effort has been devoted to modeling and field studies of environmental impact of past disposal practices. These past studies were reviewed by an independent peer review panel (EG\&G, 1988).

Early modeling studies of subsurface contaminant transport at the SDA by Pope et al., (1982), Humphrey, et al., (1982), Mizell et al. (1983) predicted that contaminants would only move a few meters in a time frame of ten thousand years. Environmental monitoring at the RWMC, however, has confirmed that organic contaminants and certain actinide elements have migrated a significant distance into the vadose zone beneath the SDA in less than thirty years (Laney, et al, 1988). This significant underestimation of contaminant movement by early studies is believed to be largely the result of: (1) an inadequate data base, (2) lack of a conceptual model of important transport processes and (3) application of computer models not suited to the unique features of the geologic setting.

The amount of quantitative information on the hydrologic and geologic characteristics of the strata beneath the SDA has improved dramatically in the last three years. This improvement is the result of extensive field and laboratory programs sponsored by INEL's Environmental Restoration Program. The present status of knowledge of the site is being documented in a report entitled "RWMC Conceptual Model." Other important references on hydrogeologic data for the site are the reports by Laney, et al, (1988), Knutson et al. (1992), McElroy (1990) and McElroy and Hubbell (1990), Borghese (1988), and Borghese (1989).

A general description of the mechanisms and factors thought to control contaminant movement in the vadose zone has been outlined by Baca and Walton (1988). Conceptual descriptions of the patterns of water movement through the fractured-porous basalt strata were developed by J. B. Robertson (EG\&G, 1988). This information was utilized in a 
preliminary performance assessment of environmental affects, which is documented in Case, et al. (1989). One of the major recommendations of that report and of a subsequent independent peer review (EG\&G, 1988) was that future performance assessments use more detailed and site-specific models for the vadose zone. This particular modeling study was motivated by this recommendation.

\subsection{PERFORMANCE ASSESSMENT ISSUES}

The U. S. Department of Energy's (DOE's) Order 5820.2a establishes policies, guidelines and minimum requirements regarding the storage, treatment and disposal of radioactive waste, mixed-waste and contaminated facilities at DOE sites (EG\&G, 1989). Chapter III of the Order requires DOE field sites to prepare and maintain a site-specific, radiological performance assessment for any low-level waste facility such as those at the RWMC. The performance assessment must provide the technical basis for reasonable assurance that the facility design and method of disposal will comply with the performance objectives of the Order.

In order to conduct a defensible performance assessment for the RWMC, a number of technical issues must be addressed regarding the various transport pathways. For the water pathway, the relevant issues are:

o How does the infiltration rate vary across the site?

o Could the past site flooding events have caused rapid migration of contaminants?

o What is the distribution of water travel-times through the vadose zone?

o At what rates does water move into the pits, trenches and through buried waste?

o Are the RWMC drainage ditches the principal source of recharge at the site?

o Do the perched water zones have an important influence on water movement?

o To what extent does water flow laterally along lithologic interfaces?

o Does the percolating water move through the vadose zone in a diffuse manner or along selected pathways?

In this study, we have attempted to address the first three issues. The remaining issues must be addressed in future studies through a combination of modeling, field and laboratory experiments. 


\subsection{OBJECIIVES AND SCOPE}

Two major objectives were pursued in this hydrologic modeling study. First, an attempted was made to gain insight into the relationships between sources of water and the patterns of water flow through vadose zone. Secondly, estimates were developed of hydrogeologic parameters that define the water transport characteristics of the site. The scope of the modeling study concentrated on three distinct aspects: (1) analysis of the infiltration rates, (2) evaluation of past flooding of Pit 10, and (3) estimation of the statistical distribution of water travel-times through the vadose zone. This information is provided for use in future radiological performance assessments of the RWMC.

The rate of infiltration and its variations across the SDA are of key importance because they have a great significance to the isolation performance of the disposal site. For example, the infiltration rate is a key input to the calculation of water travel times through the vadose zone. In addition, the rate of infiltration has a great effect on the rate of contaminant dissolution and transport from the disposal site. A water balance approach was used to estimate the infiltration rate as a function of:

o site meteorologic conditions

o soil hydraulic properties

The analysis of infiltration rates was performed using meteorologic data for two time periods: $1955-1970$ and 1982-1990. The analysis did not include a detailed evaluation of water flow through the pits, trenches, subsidence features and buried waste.

T'o evaluate the potential significance of past RWMC flooding events, simulations were performed to simulate the 1969 flooding of Pit 10. Two-dimensional computer sim rlations of water flow through the vadose zone were performed to estimate the rate and extent of the water movement that may have occurred. These simulations were performed for two representations of the vadose zone:

o equivalent porous medium and

o equivalent porous medium with a large discrete fracture.

A time period of 45 days was modeled to evaluate the characteristics of wetting front spreading and advancement. 
A probabilistic modeling technique was applied to predict the distribution of water travel-times through the vadose zone. A Monte Carlo sampling approach was used in conjunction with a one-dimensional, steady-state, unsaturated flow simulation to model the probabilistic process. A probability distribution of water travel-times was computed as a function of statistical representations of:

o the net surface water flux, i.e., annual average infiltration,

o saturated hydraulic conductivity,

o the subsurface geometry.

Important statistical properties, i.e., mean, median and variance, of water travel-time were computed. 


\subsection{PHYSICAL SETTING}

\subsection{DESCRIPTION OF MODEL STUDY AREA}

The Radioactive Waste Management Complex (RWMC) is located in the southwestern corner of the Idaho National Engineering Laboratory (INEL). It comprises about 58 hectares (144 acres) of level ground in a shall depression with surrounding low hills. The RWMC is divided into two major areas: (1) Subsurface Disposal Area (SDA) and (2) Transuranic Storage Area (TSA), which are shown in Figure 1. The 35.4 hectare ( 88 acres) SDA has been used for waste disposal since the early 1950's. The TSA has been used for waste storage above land surface since the 1970's.

Waste disposed at the SDA, which is the primary focus of this study, is buried within the surficial sediments in shallow pits, trenches and soil vaults. The surface sediments vary

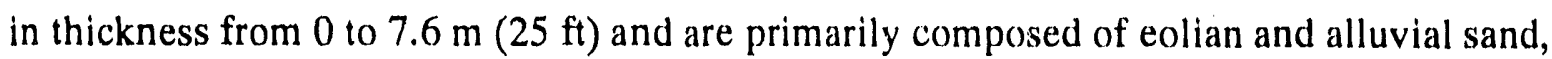
loess, and lacus'rine deposits (Barraclough, et al., 1976). These sediments are underlain by an alternating sequence of basalt flows and sedimentary interbeds.

The sedimentary interbeds are relatively thin and occasionally discontinuous. Two major interbeds occur at depths of $33.5 \mathrm{~m}(110 \mathrm{ft})$ and $73 \mathrm{~m}(240 \mathrm{ft})$. The interbeds, like the surficial sediments, are composed of silt-sized particles, with clay-sized particles ranging from 5 to 50 percent. Fine to medium sand-sized particles are common, and locally may comprise greater than 50 percent of the sediments. Small to medium gravel-sized particles are common minor constituents of the sediment beds (Barraclough, et al., 1976).

The geologic profile, however, is dominated by a sequence of basalt lava flows which constitute about $95 \%$ of the vadose zone. The basalt geology is reasonably well characterized as a result of data collection efforts by the site contractors and the U. S. Geological Survey (Anderson and Lewis, 1989; Knutson, et al, 1992). The basalt is a fractured-porous rock with its vertical permeability probably due to fractures along cooling joints. Fractures in the basalt are commonly filled with clay- and silt-sized phyllosilicates and caliche. Some of the fracture infilling material may have been transported as a suspension in water infiltrating through fracture networks (Rightmire and L.ewis, 1987). 


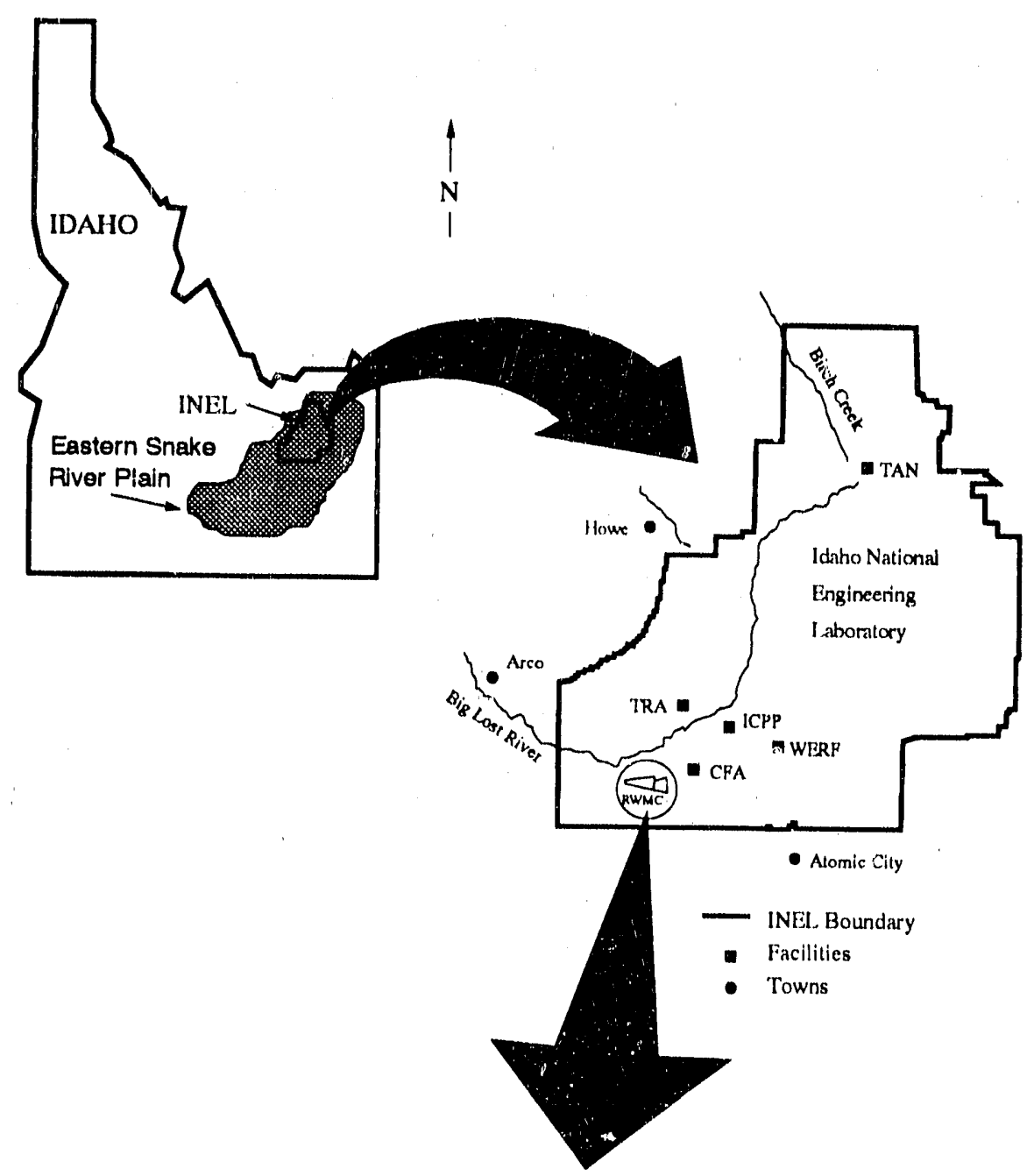

Radioactive Waste Management Complex

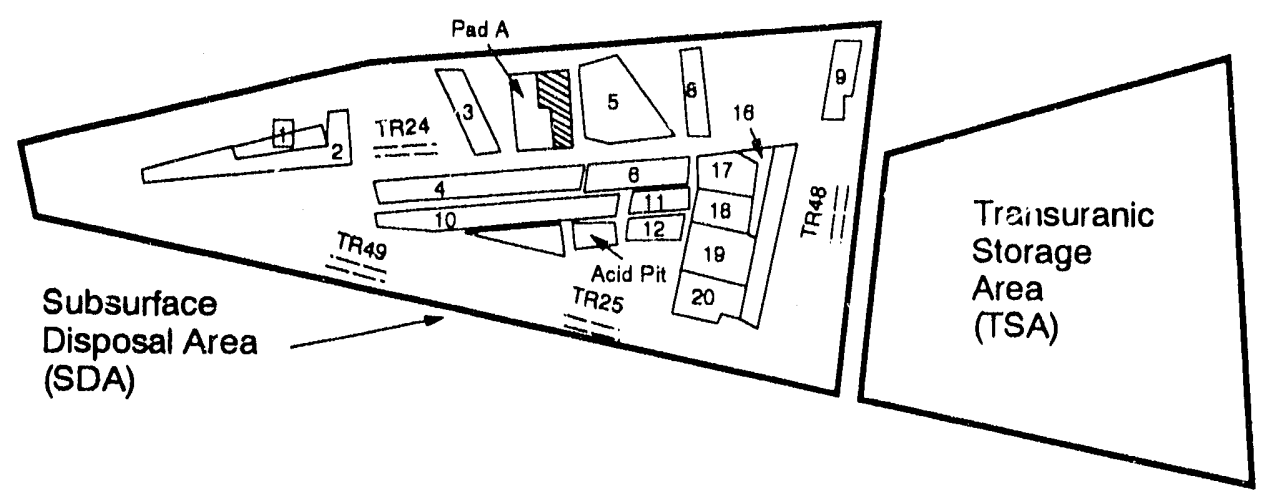

Figure 1. Location of the Radioactive Waste Management Complex 
Recent geolngical characterization hy Knutson. et al. (1002) has provided a guantitative information on the variation in structural and textural characteristics of individual basalt flows. Four generic elements are defined to describe flow characteristics. These are:

o the complete flow

o top vesicular zone

o central zone

o bottom vesicular zone

Average thicknesses of these elements are listed in Table 1. The vesicular zones (top, central and bottom) are considered to be the most permeable.

The higher permeability of the vesicular zones is attributed to the large number of fractures and open areas. Air injection tests at the RWMC and field tracer tests at other INEL locations indicate that the large scale horizontal permeabilities of basalt strata on the order of 40 to 120 Darcies. The tracer tests suggest the ratio horizontal to vertical permeability can be as high as 75 to 1 (Schmalz, 1969). In contrast, the matrix permeability of the basalt is relativcly low. For example, laboratory tests on basalt cores indicate that the median permeabilities of the lower, central, and upper elements are 4, 8, 7 milli-Darcies, respectively (Knutson et al., 1992).

Table 1. Thicknesses of Individual Basalt Flow Elements (from Knutson, et al, 1992)

\begin{tabular}{ccc}
\hline Flow Element & $\begin{array}{c}\text { Median } \\
\text { Thickness (ft) }\end{array}$ & Range (ft) \\
\cline { 2 - 2 } Top vesicular zone & 6.0 & $1-28$ \\
Central zone & 7.5 & $1-44$ \\
Bottom vesicular zone & 1.5 & $1-6$ \\
Complete flow & 15.0 & $1-56$ \\
\hline
\end{tabular}




\subsection{HYDRAULIC PROPERTIES}

In order to model the movement of soil-moisture through the vadose zone, three basic hydraulic properties are required for the surficial sediments, sedimentary interbeds, and basalt layers. These properties are:

(1) the characteristic curve which is the relation between the matric potential and moisture content,

(2) the hydraulic conductivity curve which is the relation between the relative hydraulic conductivity and matric potential, and

(3) the saturated hydraulic conductivity (and porosity).

Typically, these hydraulic properties are measured in the laboratory using small soil samples or in the field from infiltration experiments. Properties such as bulk density and porosity are also measured in the laboratory.

van Genuchten (1978 and 1980) developed closed-form empirical equations to describe the characteristic and hydraulic conductivity curves. These equations are of the general form:

$$
\theta(\psi)=\theta_{r}+\frac{\left(\theta_{s}-\theta_{r}\right)}{\left[1+(\alpha \psi)^{n}\right]^{m}}
$$

and

$$
K(\psi)=K_{s} \frac{\left\{1-(\alpha \psi)^{n-1}\left[1+(\alpha \psi)^{-m}\right]\right\}}{\left[1+(\alpha \psi)^{n}\right]^{n / 2}}
$$

where

$\theta$ is the volumetric moisture content $\left(\mathrm{cm}^{3} / \mathrm{cm}^{3}\right)$,

$\theta_{r}$ is the residual moisture content $\left(\mathrm{cm}^{3} / \mathrm{cm}^{3}\right)$,

$\theta_{s}$ is the effective porosity,

$\psi$ is the suction pressure head ( $\mathrm{cm}$ ),

$K_{s}$ is the saturated hydraulic conductivity, $\left(\mathrm{cm}^{3} / \mathrm{cm}^{3}\right)$, and

$\alpha, n, m$ are fitted parameters 
The above functions are widely used in the hydrology community and have been shown to provide excellent representations of hydraulic properties for a wide variety of soils.

A computer program RETC was developed by van Genucthen which fits the closed-form equations to laboratory data. This approach was adopted in this study to represent the characteristic and conductivity curves for both the sediments and basalt strata. Saturated hydraulic conductivity and effective porosity values were obtained from available data sources (Borghese, 1988; Borghese, . 989; Knutson et al., 1992; McElroy, 1990; McElroy and Hubbell, 1990; Bishop, 1991).

\subsection{CLIMATIC CONDITIONS}

The climate of the area is typical of a semi-arid, high desert region. Local weather data for a 22-year period indicate air temperatures from $-42 \mathrm{C}(43 \mathrm{~F})$ to $39 \mathrm{C}(103 \mathrm{~F})$. During winter, the average maximum is about $-3 \mathrm{C}(27 \mathrm{~F})$, with an average minimum of approximately $-16 \mathrm{C}(3 \mathrm{~F})$. In summer, the average temperature is about $10 \mathrm{C}(50 \mathrm{~F})$ with an average maximum is $31 \mathrm{C}(87 \mathrm{~F})$ (DOE, 1982). Air temperatures are important insofar that they affect the heat transfer in the upper few meters of the soil. Low soil temperatures, for example, reduce the saturated hydraulic conductivity because of changes in water viscosity and density.

The surrounding mountain ranges strongly influence the prevailing winds causing diurnal southwestern and nocturnal northeastern winds. The average hourly wind velocity reaches a minimum of $9 \mathrm{~km} / \mathrm{hr}(5 \mathrm{mph})$ in December and a maximum of $14 \mathrm{~km} / \mathrm{hr}(9 \mathrm{mph})$ in April and May. Calm conditions prevail about 11 per`ent of the time (DOE, 1982). These conditions are important in that they affect the rate of evaporation and heat transfer from the soil to the atmosphere.

The average annual precipitation in the vicinity of the RWMC is about $22 \mathrm{~cm}(8.7 \mathrm{in}$. with about 50 percent falling as snow (Clawson, et al., 1989). The average snowfall is 70.1 $\mathrm{cm}$ (27.6 in) with a maximum yearly snowfall of $149 \mathrm{~cm}(59.7 \mathrm{in})$. The maximum precipitation occurs in late spring and early fall. On the average, two to three severe thunderstorm days occur during the summer. The occurrence of several discrete, closely spaced, precipitation events are of particular concern because they could result in pulses of water that may enhance waste migration. Combinations of warm winds, heavy rains and snowmelt have caused past flooding at the RWMC. 


\subsection{MODELING APPROACHES}

\subsection{CONCEPTUAL FRAMEWORK AND ASSUMPTIONS}

The hydrologic processes by which meteoric water moves through an unsaturated soil are in general well understood (Hillel, 1971, Corey, 1977). Moisture movement through soil is a direct result of three factors: (1) moisture flux conditions at the air-soil interface, (2) capillary and gravity forces in the soil, and (3) hydraulic properties of the soil layers. The moisture flux at the surface varies both in time and direction (i.e., precipitation produces a positive flux whereas evapotranspiration produces a negative or outward flux) and is the primary controlling factor.

Typically, the moisture content profile in soils will exhibit three distinct zones: a dynamic zone in the upper 0.1 to $1 \mathrm{~m}$ of the soil colunin, a gradually varying zone, and then a relatively static zone at depth. The dynamic and gradually varying zones reflect the propagation and movement of undulating moisture pulses. In contrast, within the static zone the distribution of capillary pressure is relatively uniform and gravity is the dominant driving force. Large contrasts in permeability between strata commonly produce perched water zones which play important role in water movement.

In the case of unsaturated fractured rock such as the basalt layers, the physics of moisture movement are not well defined. Although the same factors are expected to be important, there is no experimental data that demonstrates applicability of porous media principles to uns aturated fractured rocks. Only recently have researchers (Wang and Narasimhan, 1985) begun to postulate relationships to describe the basic hydraulic properties of unsaturated, fractured rocks.

Because of the complexity of the actual system, a number of simplifying assumptions were made in this modeling study. They are:

o the soil surface remains bare and, therefore, there is no plant uptake of pore-water.

o the soil system is under isothermal conditions.

o the hydraulic properties of the surficial sediments, interbeds, and basalt layers are assumed to be homogeneous and anisotropic.

o the moisture characteristic curves are assumed to be non-hysteretic. 
o single phase (liquid) system (i.e., vapor phase transport is neglected and the air phase has infinite mobility).

o Darcy's law for unsaturated flow is applicable to the fractured basalt layers.

In general, the above assumptions are reasonable and applicable to the site conditions. The last assumption, however, requires validation with laboratory and/or field data.

\subsection{FLUID FLOW EQUATION AND BOUNDARY CONDITIONS}

The general equation governing isothermal flow in unsaturated soils can be derived' using the basic conservation of mass principle and Darcian flow concepts. Such derivations may be found in the textbooks by Hillel (1971), Kirkham and Powers (1972), and Corey (1977). For the case of two-dimensional fluid flow, the governing equation is given by:

$$
\left(S_{s} \frac{\theta}{\theta_{s}}+C(\psi)\right) \frac{\partial \psi^{\prime}}{\partial t}=\frac{\partial}{\partial x}\left(K_{x}(\psi) \frac{\partial \psi}{\partial x}\right)+\frac{\partial}{\partial y}\left(K_{y}(\psi)\left(\frac{\partial \psi}{\partial y}+1\right)\right)
$$

with the quantities defined as

$S_{s}$ is the specific storage coefficient, $(1 / \mathrm{cm})$

$C(\psi)$ is specific moisture capacity $(\partial C(\psi) / \partial \psi),(1 / \mathrm{cm})$

$K_{x}(\psi), \quad K_{y}(\psi)$ are the hydraulic conductivities in the horizontal (x) and vertical (y) directions, respectively.

All other quantities are as previously defined. In this formulation, the vertical coordinate is upward pointing. The boundary condition at the soil surface is given by the equations:

$$
-K(\psi)\left(\frac{\partial \psi}{\partial y}-1\right)=P(t)-E(t)
$$

where $P(t)$ is the moisture flux from precipitation and $E(t)$ is the moisture flux by evapotranspiration. The boundary condition at the bottom of the soil column is, in some cases, assumed to have a constant pressure head:

$$
\psi\left(x, y_{\min }\right)=\psi_{o}
$$


which corresponds to a saturated condition of $\psi=0$, i.e., water table. A free-drainage boundary condition was also used in certain applications. This boundary conditions assumes a zero gradient in pressure head arnd is given by:

$$
q=-K(\psi)
$$

where $q$ is the Darcy moisture flux.

In the abse'sce of field measurements, the initial moisture conditions were computed to be consistent with the average moisture flux condition and the specified hydraulic properties. Typically, the initial conditions were obtained by performing steady-state or cyclic simulations.

\subsection{DESCRIPTION OF COMPUTER CODES}

A number of computer codes have been developed and acquired to unsaturated flow in the RWMC vadose zone. The primary codes used in this modeling study were: (1) UNSAT-H (Fayer and Jones, 1990), (2) FLASH (Baca, et al. 1992), (3) PORFLOW (Runchal and Sagar, 1990), and (4) FLOWMC (Nguyen, et al, ,1992). Summary descriptions of these computer codes are presented in the appendix. Principal reasons for selection of these particular codes are:

(1) the computer codes have been verified against known solutions, benchmarked against other computer codes, and tested using actual field data.

(2) the unique capability of the codes to handle layered systems with large contrasts in hydraulic properties.

(3) the code availability and user familiarity.

(4) the codes have been applied successfully to model moisture transport in arid site environments.

(5) the code is computationally efficient and therefore inexpensive to use.

The selection was also based on results of previous verification and benchmark testing of a number of available codes (Baca and Magnuson, 1990, Magnuson et al., 1990). The four computer codes are installed on the onsite CRAY X-MP model 24 computer and are maintained under a formal software $\mathrm{QA}$ and configuration management control procedure (Baca, 1990). 


\subsection{WATER FLOW THROUGH SURFICIAL SEDIMENTS}

\subsection{INTRODUCTION}

The rate at which water percolates into the vadose zone is an important factor because it controls, to a large degree, the dissolution and transport of contaminants. Pore-water is typically transported downward by gravity and capillarity. However, not all the water that enters the surface sediments infiltrates to depth or reaches the water table. Under certain meteorologic conditions, the pore-water may be brought back to the surface and lost to the atmosphere. A simulation of water movement through the surficial sediments was conducted to estimate the net downward moisture flux that occurs within the SDA.

Cross-sections were conscructed for two idealizations, one of the surficial sediments and another for a typical disposal pit. The first idealization consisted of a $3 \mathrm{~m}$ homogeneous layer of undisturbed native sediments which was underlain by $3 \mathrm{~m}$ of vesicular basalt. The $3 \mathrm{~m}$ layer of sediment corresponds to the average thickness estimated by Anderson and Lewis (1989). The pit or disturbed cross-section consisted of a $1 \mathrm{~m}$ thick soil cap followed by $1 \mathrm{~m}$ of waste and backfill; this was underlain by $1 \mathrm{~m}$ of undisturbed sediments and $3 \mathrm{~m}$ of vesicular basalt. The cross-sections for both representations are depicted in Figure 2.
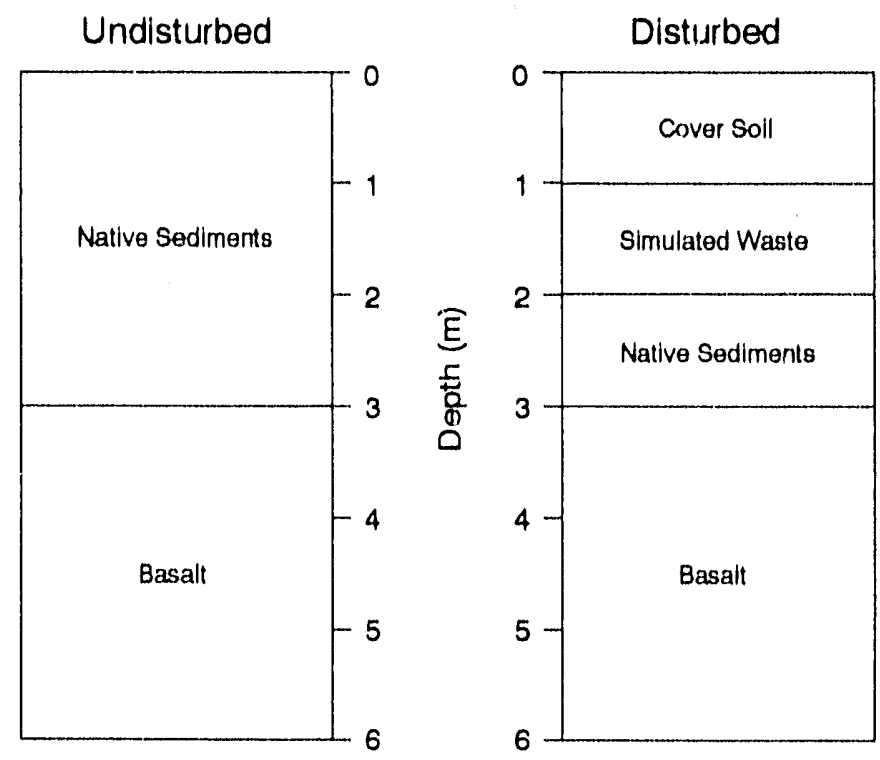

Figure 2. Cross-sections for Surficial Sediments and Basalt 


\subsection{PARAMETERIZATION OF HYDRAULIC PROPERTIES}

An extensive amount of data exists describing the hydraulic properties of the surficial sediments comprising the RWMC site. However, values for certain hydraulic properties, presented by separate investigators, often differ by as much as an order of magnitude. The currently available data on hydrauiic properties is presented in the reports by Borghese $(1988,1989)$, McElroy and Hubbell (1990) and Bishop (1991).

Borghese (1988) sampled the emplaced soil cover at fourteen locations within the SDA. The cover consisted of soil brought in from the spreading areas and was emplaced to improve surface drainage within the SDA. Hydraulic conductivities, bulk density, and porosities were determined for each of these samples. The samples from two of these locations also had characteristic curves determined (Borghese, 1989). Geometric averages of Borghese's (1989) hydraulic conductivity and porosity data were used to represent the emplaced cover for the pit profile. Characteristic curve data were arithmeticaliy averaged before using RETC program to obtain the best representation of the moisture characteristic curve. The resulting shape of the curve was modified slightly to assure a reasonable air entry pressure. This was accomplished by increasing the $\alpha$ parameter.

Because of the widely varied contents of the waste pits and trenches at the RWMC, a reliable estimate the representative hydraulic properties for the disturbed soils within the pits and trenches is unavailable. The hydraulic properties of the waste pits were assumed to be same as those for the cover since both are disturbed soils.

The hydraulic properties selected for the undisturbed sediments were taken from McElroy and Hubbell (1990)). Thirty-five sediment samples from the SDA surface and interbeds were retrieved from archived cores dating from 1986 to 1988. These samples were tested to determine the hydraulic conductivity and characteristic curves. The geometric means of the hydraulic properties from four surficial sediment samples were used in the moisture flow simulation.

Hydraulic properties for basalt were obtained from Bishop (1991). In this study core samples of vesicular basalt from the RWMC were tested for hydraulic conductivity and characteristic curves. The reported conductivities were increased to the equivalent of 40 Darcies, which is considered to be more representative of field scale conductivity, as discussed earlier. 
These values represent an attempt at determining representative properties for each material required in the simulation. The corresponding characteristic curves are show $n$ in Figure 3. The parameter values used in the infiltration simulations are given in Table 2.
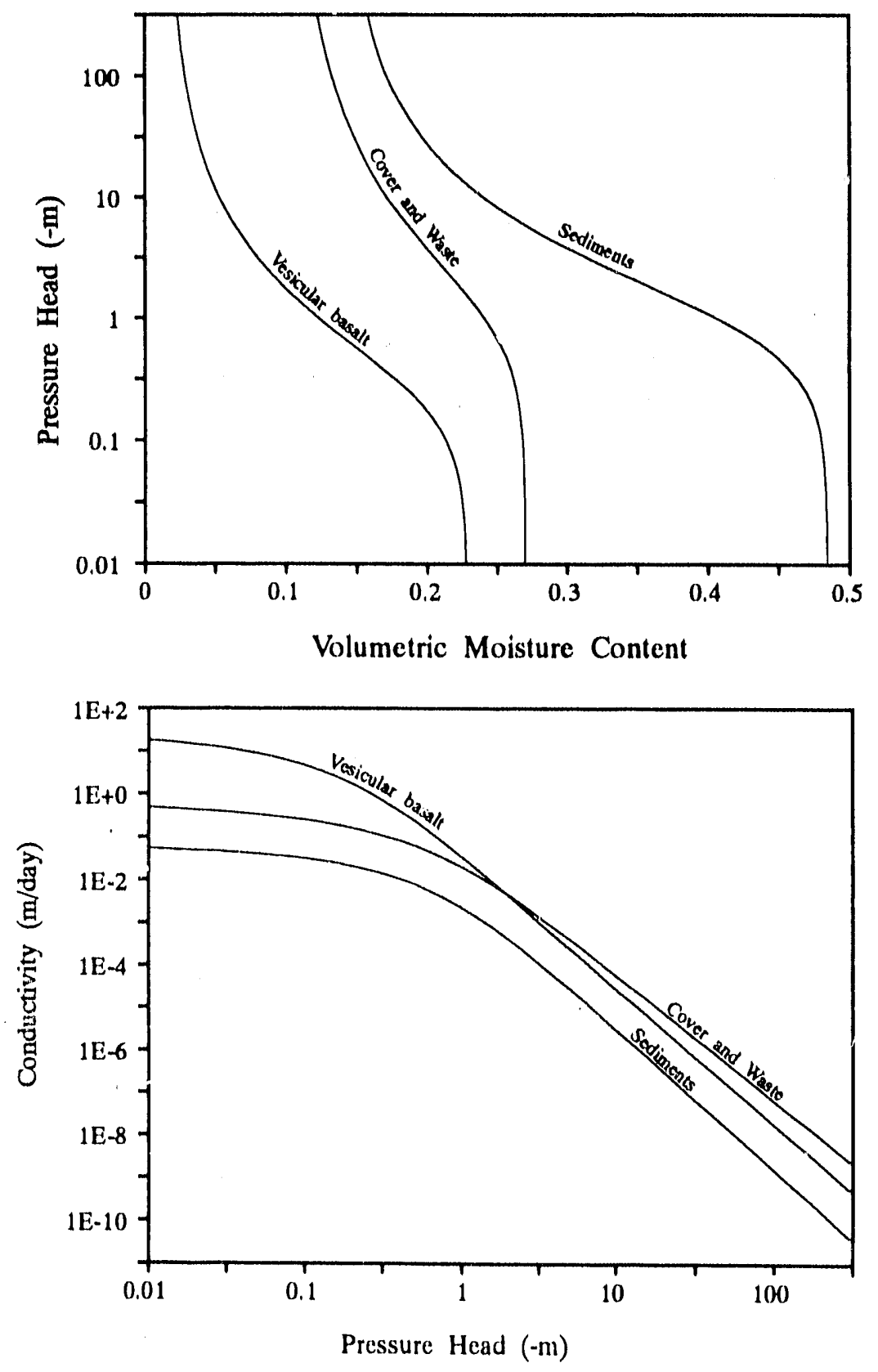

Figure 3. Characteristic and Conductivitv Curves for Sediments and Basalt 
Table 2. van Genuchter Parameters for Sediments and Basalt

\begin{tabular}{rccccc}
\hline Material & $K_{s}(\mathrm{~m} / \mathrm{day})$ & $\theta_{s}$ & $\theta_{r}$ & $\alpha\left(\mathrm{m}^{-1}\right)$ & $n$ \\
Cover and Waste & 0.7128 & .270 & .104 & 1.500 & 1.502 \\
Sediment & 0.0656 & .484 & .142 & 1.066 & 1.523 \\
Vesicular Basalt & 29.290 & .228 & .015 & 3.840 & 1.474 \\
\hline
\end{tabular}

\subsection{METEOROLOGIC DATA}

Site specific meteorological data was required in order to compute the net moisture flux at the soil surface. The meteorological parameters required are maximum and minimum air temperature, dewpoint temperature, solar radiation, average wind speed, average cloud cover, and daily precipitation. The majority of this meteorological data was obtained from the NOAA weather station at Pocatello. Data from this location was used rather than that from either a USGS micrometeorological station just north of the RWMC or a NOAA weather monitoring stations at the Central Facilities Area (CFA) because neither of these stations historically have measured dew point. The dev' point can be calculated from humidity measurements, but these were not available either. Current measurements at both the RWMC and at CFA are now much more extensive than those taken previously.

An option considered and discarded was combining the measurements at Pocatello and CFA. This option was not used because it was felt that a self-consistent data set was necessary. Weather patterns make it quite possible that conditions at each location can be different. Therefore combining data sets might result in inconsistencies between measured values such as daily temperatures and wind speed at one location and humidity at another. For this reason, the NOAA data from Pocatello was used. However, even this data set was not complete in that wind speed measurements were missing from an earlier time period. The missing data was supplied from the weather station at CFA. 
In summary, weather data for two periods were constructed directly and indirectly from the available data. The first period was from 1955 to 1964 and the second period being 1984 to 1990 . The period 1955-1964 consisted of maximum and minimum dally temperatures, precipitation, average cloud cover (calculated from minimum dewpoint and maximum tempcrature), and dewpoint (calculated from relative humidity) from the Pocatello airport; solar radiation data was generated using the WGEN computer program (Richardson and Wright, 1984); and wind speed from the Central facilities Area of the INE: . Period 1984-1990 consisted of all parameters, except solar radiation, originating from the Pocatello airport. Solar radiation for this second period was also generated using WGEN.

The missing cloud cover data for the first model period was obtained by first averaging the known sky cover over the period of 1984-199(). The averaged data provided the seasonal shape and characteristic, but eliminated all extremes normally found in the sky cover data. Secondly, extremes were reintroduced into the cloud cover data by analyzing other known parameters and finding a possible correlation between cloud cover and the other available parameters. The minimum dewpoint and the maximum temperature were found to have the strongest correlation with cloud cover and a functional relationship was found to generate the missing extremes in the cloud cover data.

The missing dewpoint data was calculated directly from relative humidity and temperature using psychometric tables. The missing solar radiation of both modeling periods was generated with WGEN which generates daily precipitation, temperature, and solar radiation values using statistical principles. The program was run with an option chosen to read actual p ecipitation and average temperature values allowing the program to generate conditional solar radiation values.

Because the daily precipitation includes forms of precipitation inciuding rainfall, snow and hail, the precipitation values were modified to account for the accumulation and melting of snow, along with the possibility of frozen ground. Values of water equivalent of snow on the ground were provided by NOAA for the Pocatello airport. An increase in water equivalent of snow on the ground was subtracted from the daily precipitation and likewise a decrease in water equivalent of snow on the ground was added to the daily precipitation. If there was a precipitation event when the maximum temperature was below $31^{\circ} \mathrm{F}$ only the water equivalent of snow on the ground was allowed to increase. Any decrease in water 
equivalent on the ground during these cold days was assumed lost to sublimation. These adjustments of precipitation rates did not significantly change the annual cumulative precipitation values.

\subsection{SIMULATIONS OF PORE-WATER MOVEMENT}

The long-term patterns of pore-water movement were modeled as a function of the moisture flux across the soll surface and the hydraulic properties of the vadose zone. A time varying flux was used as the upper boundary condition, as daily precipitation, while the lower boundary condition was specified as a unit gradient. The lower boundary condition selection was valid because the bottom boundary is located $6 \mathrm{~m}$ below the surface were upward flow is highly unlikely. The model also included evaporation at the surface and vapor flow within the soll column.

Initial conditions for the start of the earlier modeling period was found by running the simulation repetitively with the 1955 weather data until a quasi steady-state condition was achieved. This had the effect of assuming the weather data for each preceding year was exactly the same. The condition was achieved when the net yearly flux everywhere in the vesicular basalt converged to a constant value. The initial conditions for each succeeding year was then simply taken from the year end values of the previous year. Because meteorologic data for 1964 through 1984 were not available, this time period was not simulated.

The yearly net flux values for the simulation results are shown in Figure 4 . The drainage from the bottom of each profile represents the net infiltration. For the undisturbed scenario the minimum and maximum drainage for the simulation periods was 0.91 and 1.87 $\mathrm{cm}$, respectively. Fer the pit scenario, the corresponding values were 0.66 and $1.85 \mathrm{~cm}$. This net yearly drainage is essentially the same for each profile.

The daily fluxes for depths of $0,50,150,350$, and $600 \mathrm{~cm}$ for the period 1962-1964 are shown in Figures 5 and 6 . The surface flux for both the undisturbed and the pit profiles was the same. As was seen previously, the higher conductivity cover and waste results in the same net infiltration. However, the amplitude of the infiltration peaks is greater with the higher conductivity cover and waste. This can be easily seen in Figures 5 and 6 . In both 


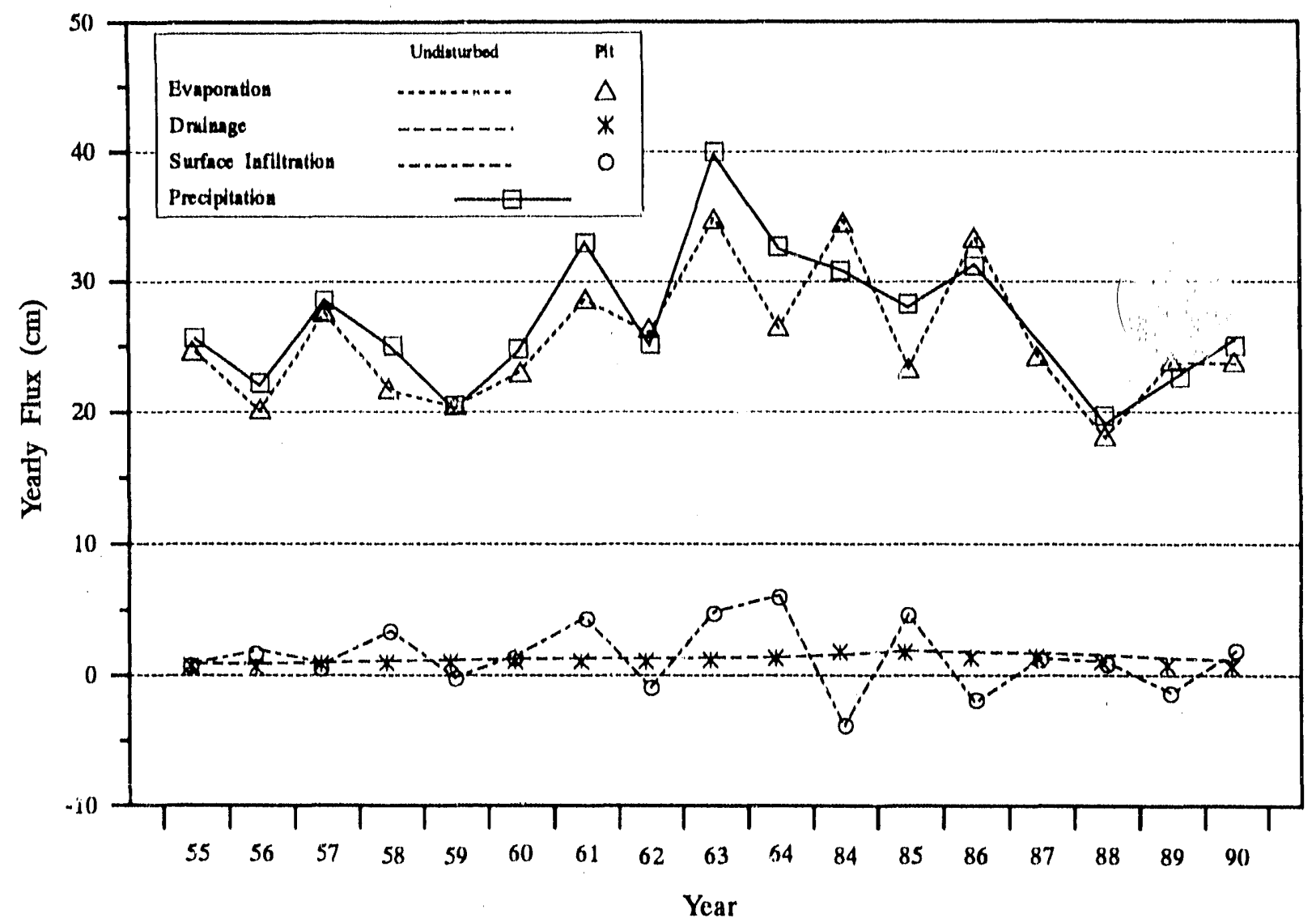

Figure 4. Computed Moisture Flux Totals for 1955 through 1990

profiles the amplitude dampens with depth, as was expected. The pit profile allows the effect of surface evaporation to reverse the flow direction to a greater depth than the undisturbed case. 

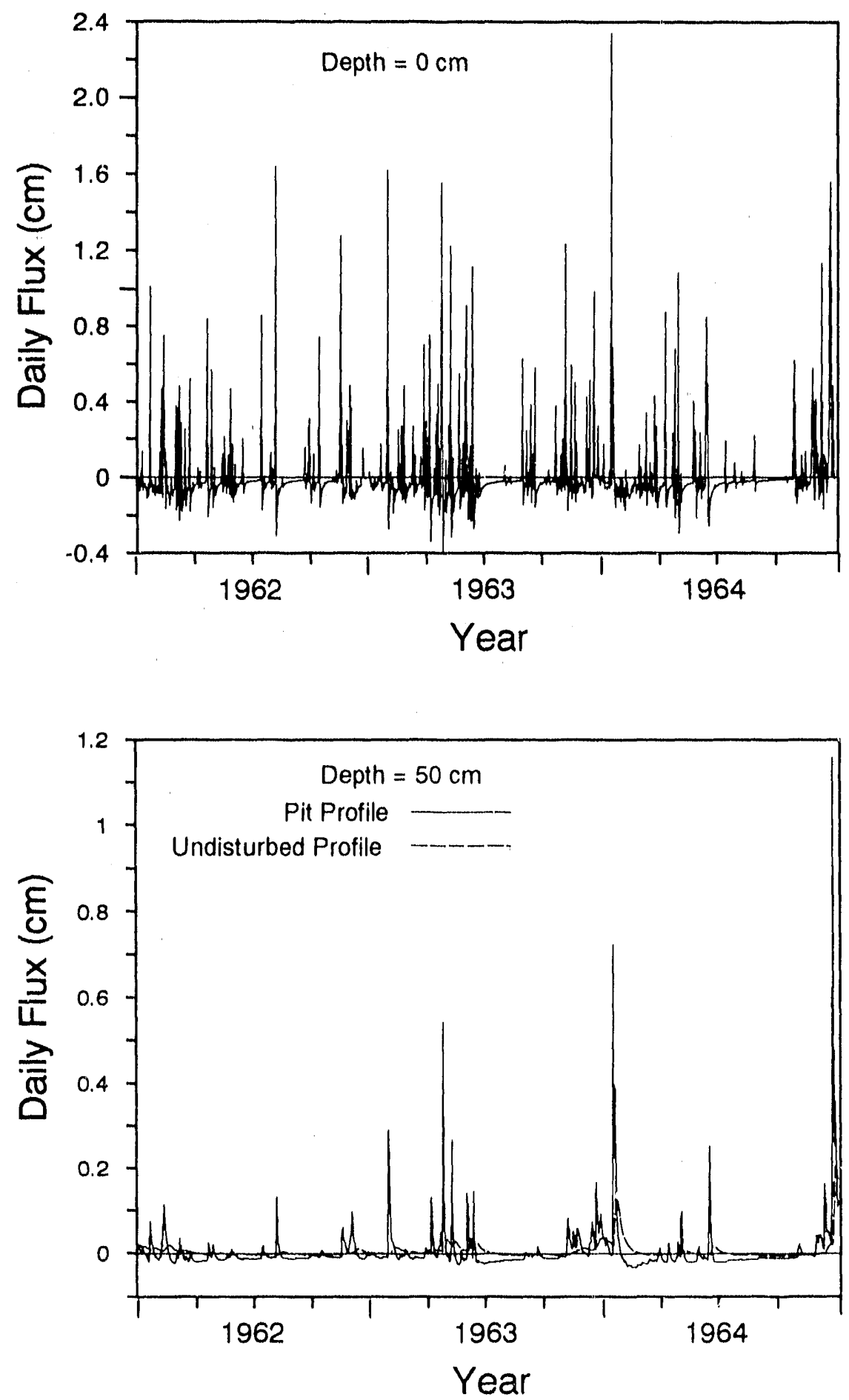

Figure 5. Daily Fluxes for Soil Surface and $50 \mathrm{~cm}$ depth 

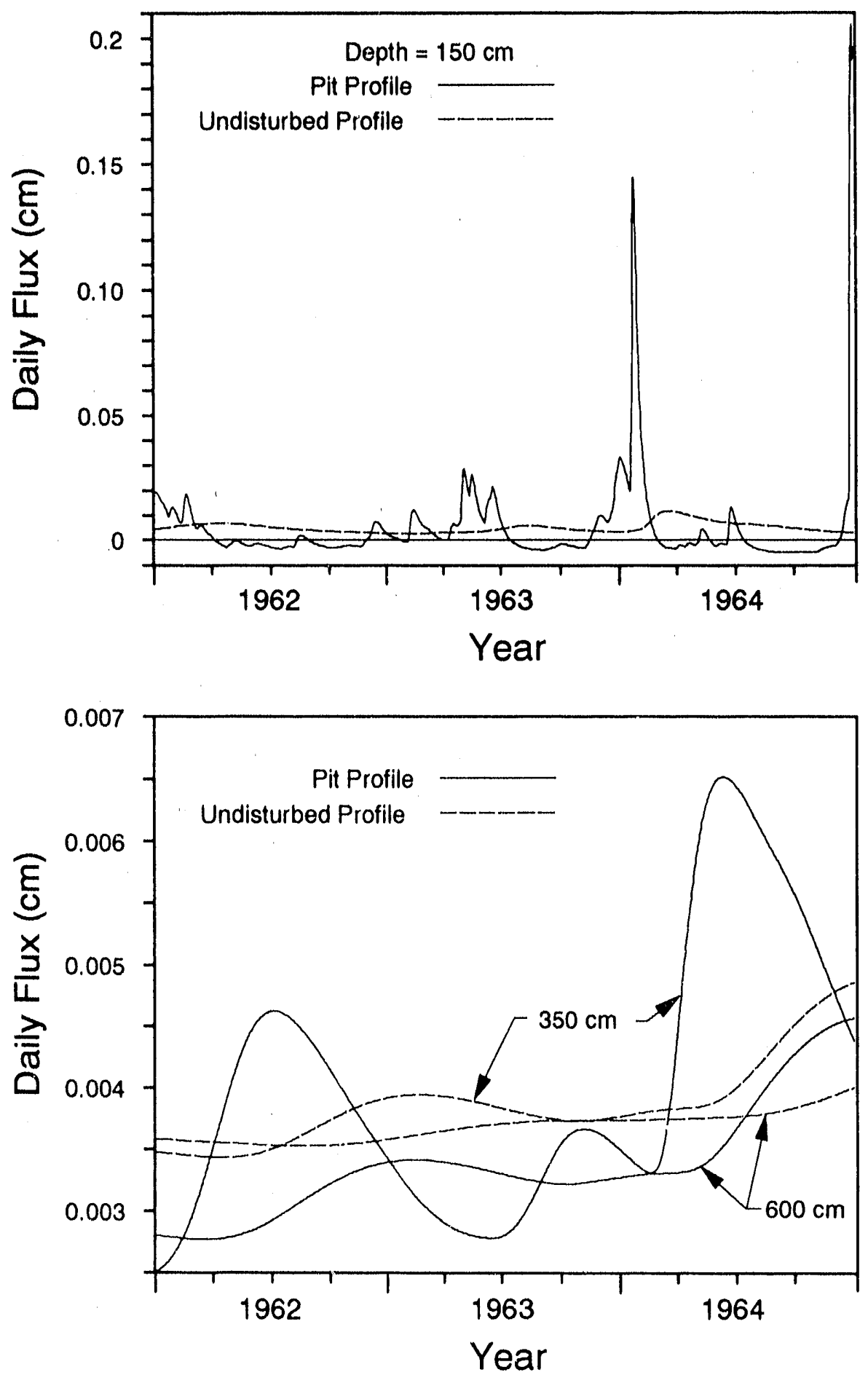

Figure 6. Daily Fluxes for 150 and $350 \mathrm{~cm}$ depth 


\subsection{WATER FLOW FROM FLOODING EVENTS}

\subsection{INTRODUCTION}

Flooding of the RWMC occurred on three separate occasions, namely 1962, 1969, and 1982. Rainfall, rapid snowmelt, and accumulation of local runoff (Vigil, 1988) resulted in flooding of a number of open pits and trenches. Infiltration of water from these events is a likely mechanism by which radionuclides have been transported through the vadose zone and down to the $110 \mathrm{ft}$ interbed (Rawson et al., 1989). This simulation study was conducted to assess the rate and extent of water movement during such flooding events. The 1969 flooding of Pit 10 was selected because it was one of the larger flooding events at the RWMC.

The geologic setting beneath Pit 10 consists of surface sediments, vesicular basalt, massive basalt, and sedimentary interbeds. The hydraulic properties for each of these materials vary spatially both in the vertical and horizontal directions. The stratigraphy was idealized as sequence of uniformly thick and homogeneous layers. For convenience in simulating water flow through the vadose zone, average properties were assigned for each layer.

Simulations were performed for two particular cases: (1) the subsurface consists of horizontal porous layers with averaged hydraulic parameters with the effect of the fractures in the basalt included by increasing the overall hydraulic conductivity, and (2) similar stratigraphic setting with the addition of a vertical, through-running fracture. The objective of including a single fracture in the stratigraphic model was to assess the possible effects of a preferential and fast pathway.

\subsection{PARAMETERIZATION OF HYDRAULIC PROPERTIES}

For each distinct layer in the conceptual model, a number of parameters were needed to describe the hydraulic properties. These parameters were the saturated hydraulic conductivity, effective porosity, specific storage capacity, and curves describing the functional relationship between pressure head and volumetric moisture content and between hydraulic conductivity and pressure head. The analytical models developed by van Genuchten (1978) and Mualem (1976) were used to describe these curves. The characteristic and hydraulic conductivity curves developed from available data are summarized in Figure 7. 

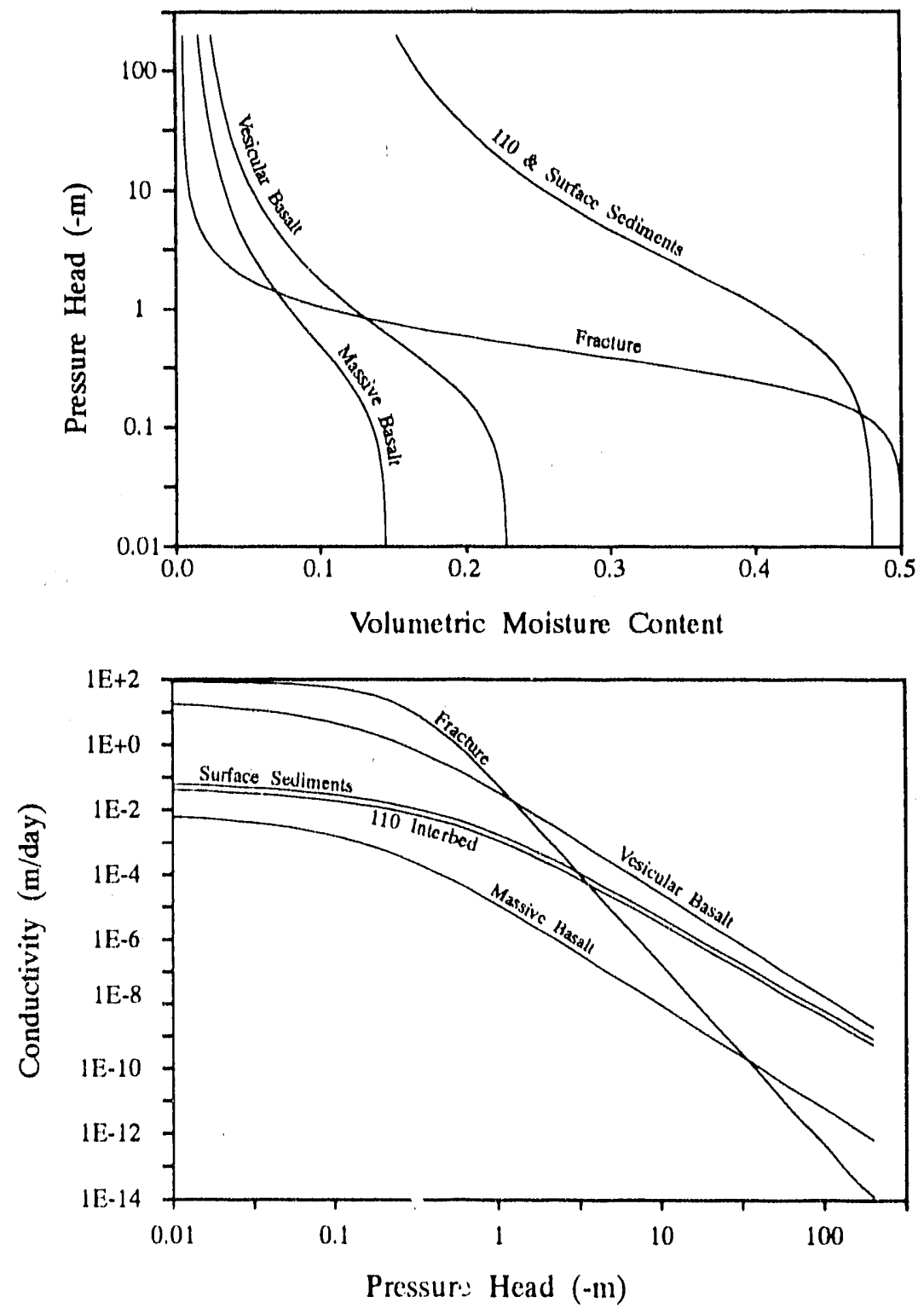

Figure 7. Characteristic and Conductivity Curves for Vadose Zone

The specific storage was assumed to be the same for all layers and was assigned the value $1 \times 10^{-2} \mathrm{~cm}^{-1}$. The saturated hydraulic conductivity was treated as isotropic for each material except the vesicular basalt which was assigned a horizontal conductivity that was three times the vertical conductivity. The selection of the hydraulic parameters for each of the material types were derived from available field and laboratory data. The hydraulic parameter values used in the simulation are shown in Table 3. 
Table 3. van Genuchten Parameters for Vadose Zone

\begin{tabular}{cccccc}
\hline Material & $K_{s}(\mathrm{~m} / \mathrm{day})$ & $\theta_{s}$ & $\theta_{r}$ & $\alpha\left(\mathrm{m}^{-1}\right)$ & $n$ \\
Sediments & 0.100 & 0.480 & 0.100 & 1.216 & 1.360 \\
Interbed & 0.0656 & 0.480 & 0.100 & 1.216 & 1.360 \\
Vesicular Basalt & 29.29 & 0.228 & 0.015 & 3.840 & 1.474 \\
Massive Basalt & 0.010 & 0.145 & 0.015 & 3.840 & 1.474 \\
\hline
\end{tabular}

The saturated hydraulic conductivity of the surficial sediments was obtained in a different manner. Basically, the $K_{s}$ value was estimated by dividing the pit depth by the estimated drain time. While the exact length of time Pit 10 remained flooded could not be determined, indirect evidence suggested that the pit remained flooded for sixty days or longer. Using information from Vigil (1988), the depth of water in Pit 10 was estimated to be about $6 \mathrm{~m}$. Assuming a $6 \mathrm{~m}$ depth of water and a 60 days drain time, the hydraulic conductivity of the surficial sediments would have to be on the order of $0.1 \mathrm{~m} /$ day. This value compares favorably with the average $K_{s}$ value of $0.065 \mathrm{~m} /$ day from McElroy and Hubbell (1990). 


\subsection{INITIAL AND BOUNDARY CONDITIONS}

Because Pit 10 is considerably longer than it is wide, a cross-section along the shorter axis was chosen for simulation. This choice of a cross-section has a plane of symmetry across the center of the pit so only one half the domain, or $15 \mathrm{~m}$ needed to be modeled. Considerable effort was spent in refining the vertical mesh refinement in order to achieve an adequate pressure-head solution. The final grid used 305 nodes in the vertical direction and 60 nodes in the horizontal. This grid extended $60 \mathrm{~m}$ in the horizontal and $37 \mathrm{~m}$ below land surface. This depth extended to well below the $110 \mathrm{ft}$ interbed. The top of the modeled domain represents a horizontal plane intersecting the bottom of the pit.

The surface boundary conditions consisted of: (1) a flux equal to the saturated hydraulic conductivity for the pit area and (2) a background flux of $0.05 \mathrm{~m} / \mathrm{yr}$ for that portion of the surface outside the pit. A flux of twice that calculated from the infiltration analysis was used to ensure the results were conservative. A higher background flux resulted in wetter conditions which yielded initially higher conductivities and shorter water travel-times.

The lateral boundaries were treated as no-flux boundaries. The inner boundary at the center of the pit could be treated in this fashion as a result of the symmetry plane. The direction of water movement at the outer boundary was strictly vertical during the period of the simulation and could therefore be treated as a no-flux boundary.

The depth to the bottom boundary was selected to be within the vesicular basalt below the $110 \mathrm{ft}$ interbed. The bottom boundary condition was set at a prescribed head. This boundary condition fixes the hydraulic conductivity and an artificially low conductivity layer would be imposed at the lower boundary. The limitation, then, is that the flooding simulations could only be carried out to that point in time when the wetting front begins to contact the lower boundary.

The initial conditions for the flooding simulation were obtained by solving for the steady-state pressure heads with the background infiltration prescribed over the entire top boundary of the modeled domain. The resulting pressure head profile for a one-dimensional slice down through the model is shown in Figure 8 and was distributed horizontally in the two-dimensional representation. 


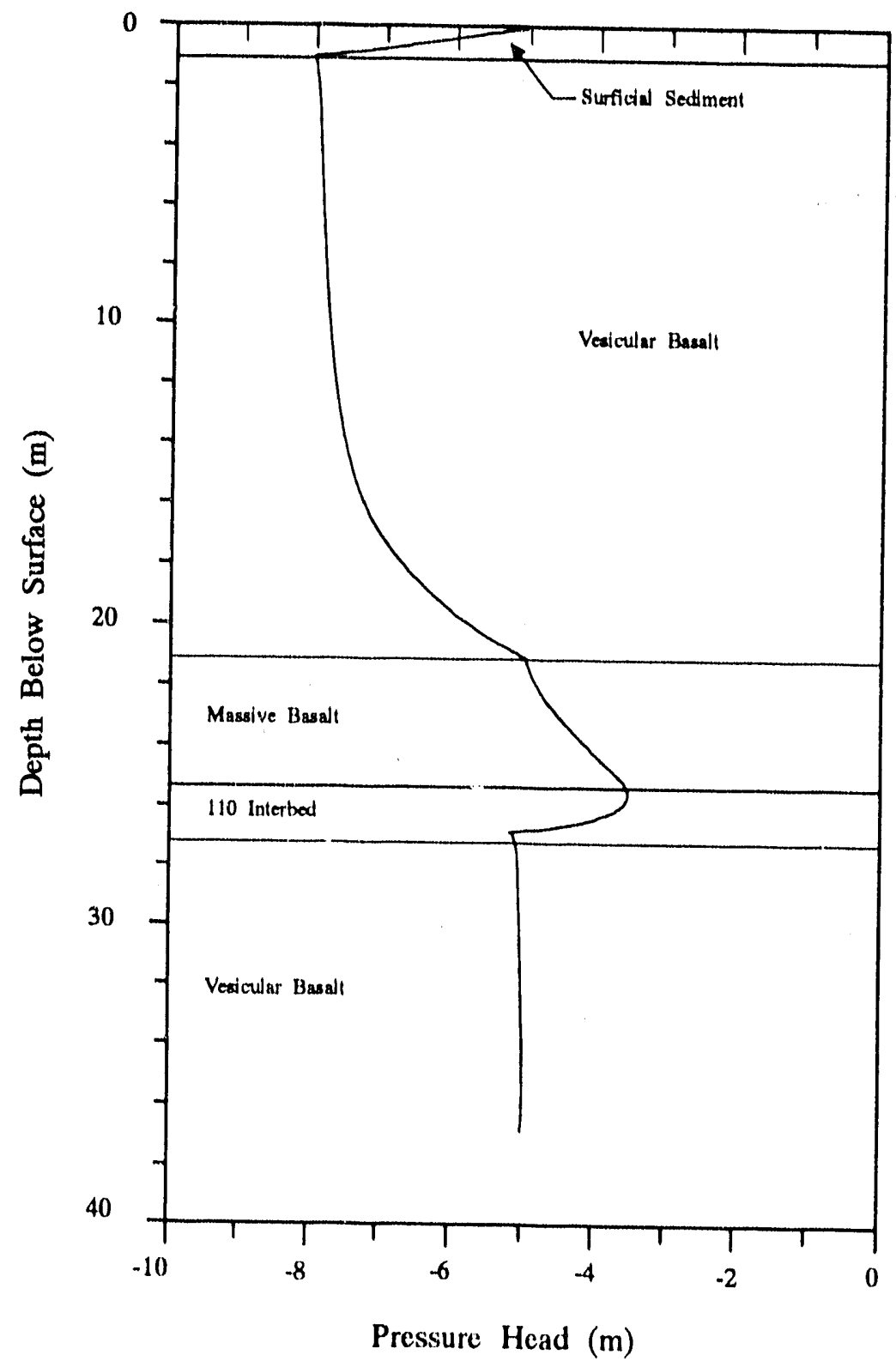

Figure 8. Initial Conditions for Pit 10 Simulation 


\subsection{SIMULATIONS OF WETTING FRONT ADVANCE}

\subsubsection{Base Case Flooding Scenario}

The base case for flooding of Pit 10 at the RWMC used a subsurface geometry consisting of flat, uniformly thick, stratigraphic units. The pressure head profiles for the base case simulation at iwo selected time planes are shown in Figures 9 and 10. The time planes were chosen to illustrate the progression of the wotting front and the perching that occurs when the wetting front reaches the low conductivity massive basalt. Because of the anisotropy of the hydraulic conductivity assigned to the vesicular basalt, appreciable spreading occurred within the unsaturated portion of vesicular basalt in addition to the marked spreading of the perched water body.

As can be seen the wetting front advances rapidly to a depth of $20 \mathrm{~m}: \mathrm{n} 25$ days and then begins spreading laterally as a perched water body. This simulation demonstrates that even with this simple conceptual model for flow, the flooding of Pit 10 and resultant infiltration of water provides a likely pathway for the migration of contaminants downwards to the $110 \mathrm{ft}$ interbed. The lateral spreading of the perched water body had not stopped at the last time plane corresponding to 45 days after initiation of the flooding. If the simulation had been run longer, the lateral domain would need to be extended to prevent the no-flux boundary from influencing the spread of the perched water body.

From Figure 10, it is evident that a saturated region that persists in the surficial sediments below the pit. This is a result of the infistration rate being equal to the hydraulic conductivity. The vesicular basalt underlying the sediments has a higher conductivity and drain more readily, which in turn, prevents the vesicular basalt from becoming saturated.

\subsubsection{Scenario with Discrete Fracture}

The second simulation of flooding of Pit 10 duplicated the conditions of the base case but had a single through-running fracture imposed. This hypothetical fracture was $0.005 \mathrm{~m}$ in width and began just below the surficial sediment-vesicular basalt interface. The fracture did not contact the surficial sediment. Likewise the bottom of the fracture was slightly above the 110 interbed-massive basalt interface. The fracture was hypothesized to be filled with a highly drainable sediment. 

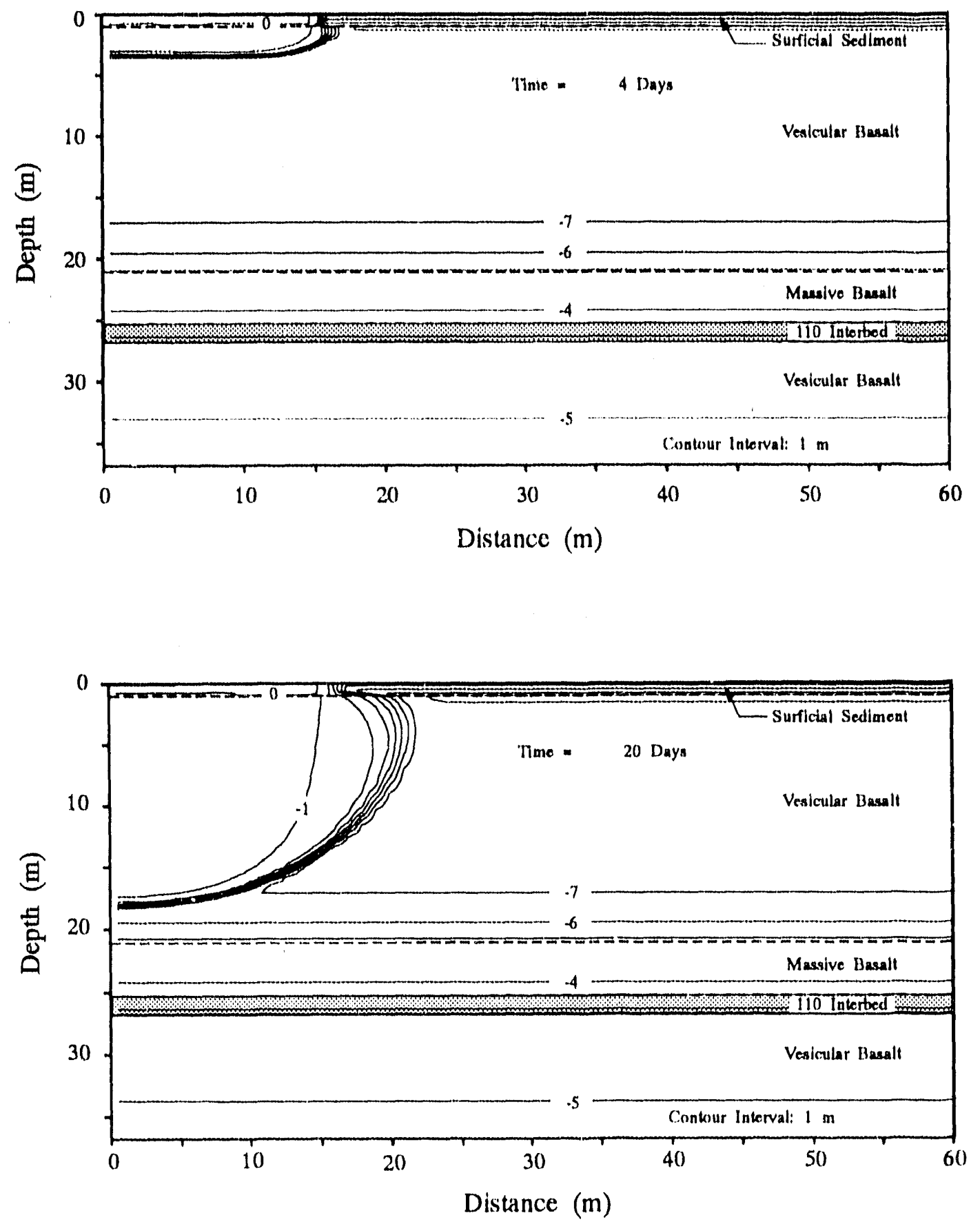

Figure 9. Base Case - Pressure Heads at 4 and 20 days 

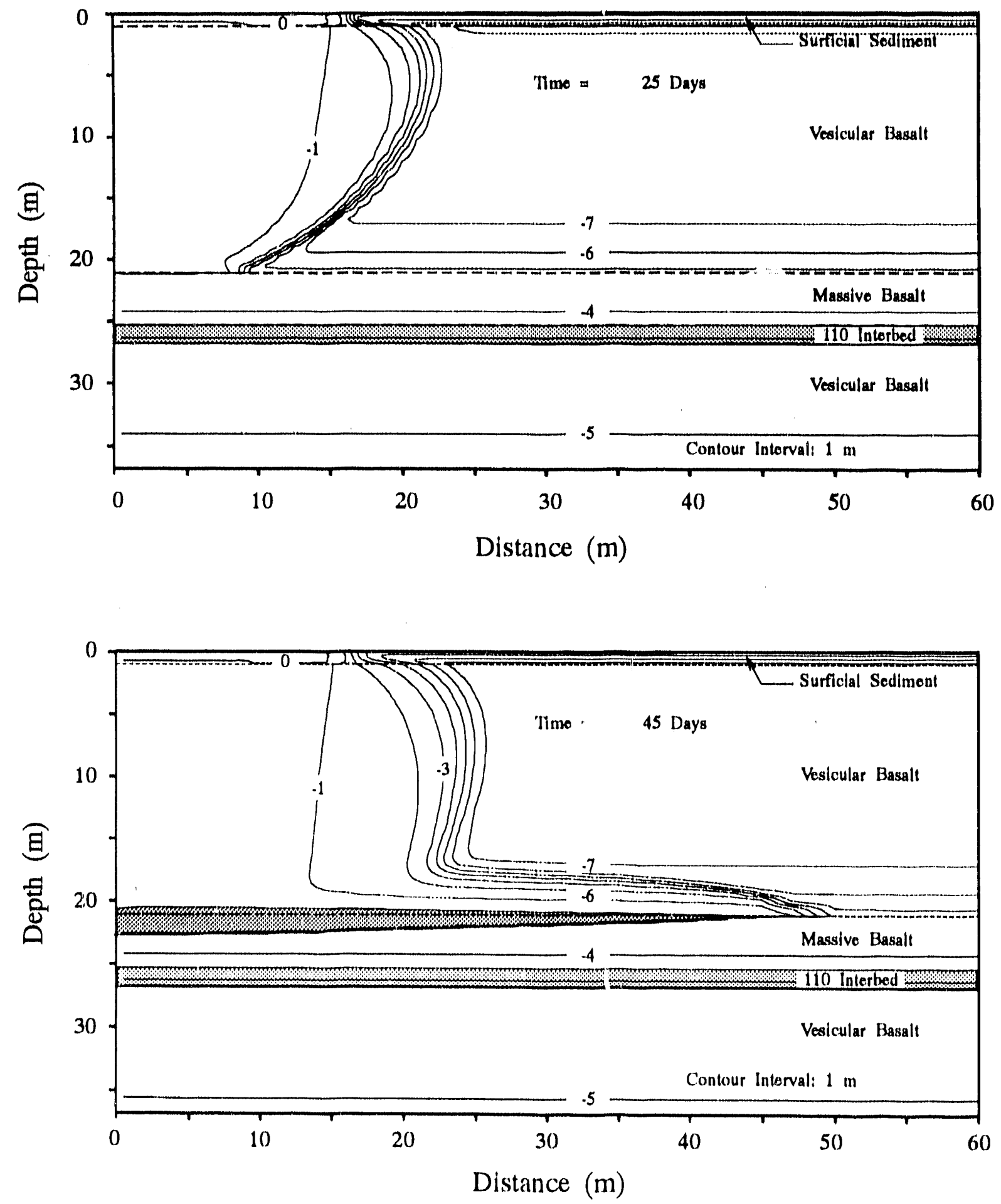

Figure 10. Base Case - Pressure Heads at 25 and 45 days 
The cholce of distributed network of fractures would be more realistic than a single through-running fracture. However, there is little if any information on the distribution of fractures and their apertures, making it difficult to select a realistic fracture pattern. By using a single, connected fracture, the simulation is conservative in that water movement along the fracture can continue uninterrupted.

Pressure head profiles for the fracture case are shown in Figures 11 and 12 for at the same times as in the previous simulation. The effect of the fracture does not become obvious until the wetting front contacts the massive basalt. By comparing the moisture characteristic curves (see Figure 6) for the vesicular basalt and the fracture at the pressure behind the wetting front ( $\sim-1 \mathrm{~m}$ of tension) it can be seen that the conductivities of both are essentially the same. This explains why there is no immediate effect from the fracture, it remains essentially drier than the surrounding vesicular basalt even during the flooding. It is important to state, however, that the actual hydraulic behavior of large fractures in basalt strata is not well understood at the present time.

Once the wetting front reaches the basalt, however, a quite different result occurs. The matric potential increase (become less negative) to the point where the fracture is more conductive than the basalt. Water rapidly moves down the fracture and into the $110 \mathrm{ft}$ interbed. A "bulb" of saturated water extends downward across the $110 \mathrm{ft}$ interbed. The saturated condition cannot persist across the $110 \mathrm{ft}$ interbed-vesicular basalt because the vesicular basalt has a higher conductivity and the water drains away from the $110 \mathrm{ft}$ interbed. The wetting front can still be observed below the $110 \mathrm{ft}$ interbed in terms of the greater pressure heads. 

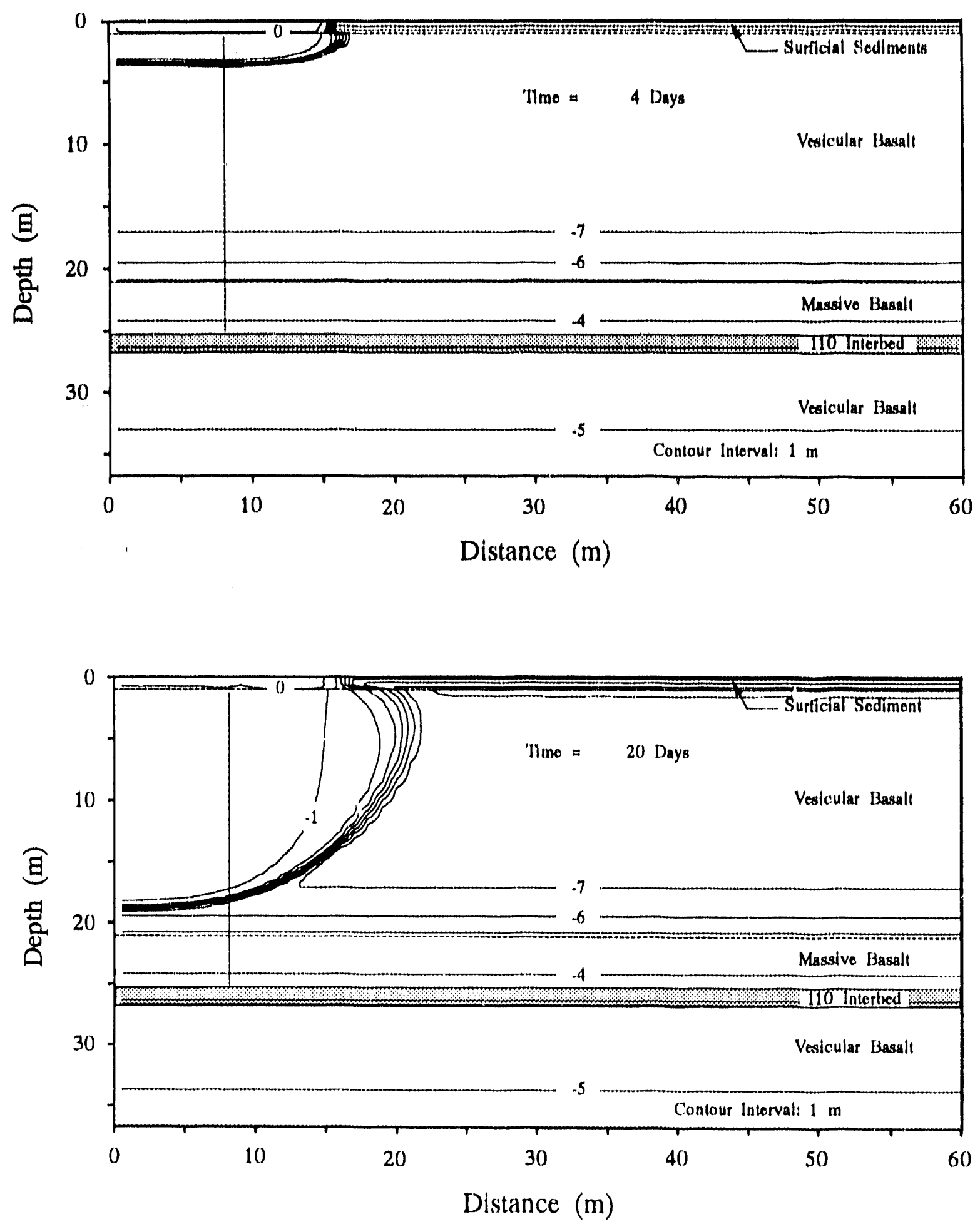

Figure 11. Fractured Case - Pressure Heads at 4 and 20 days 

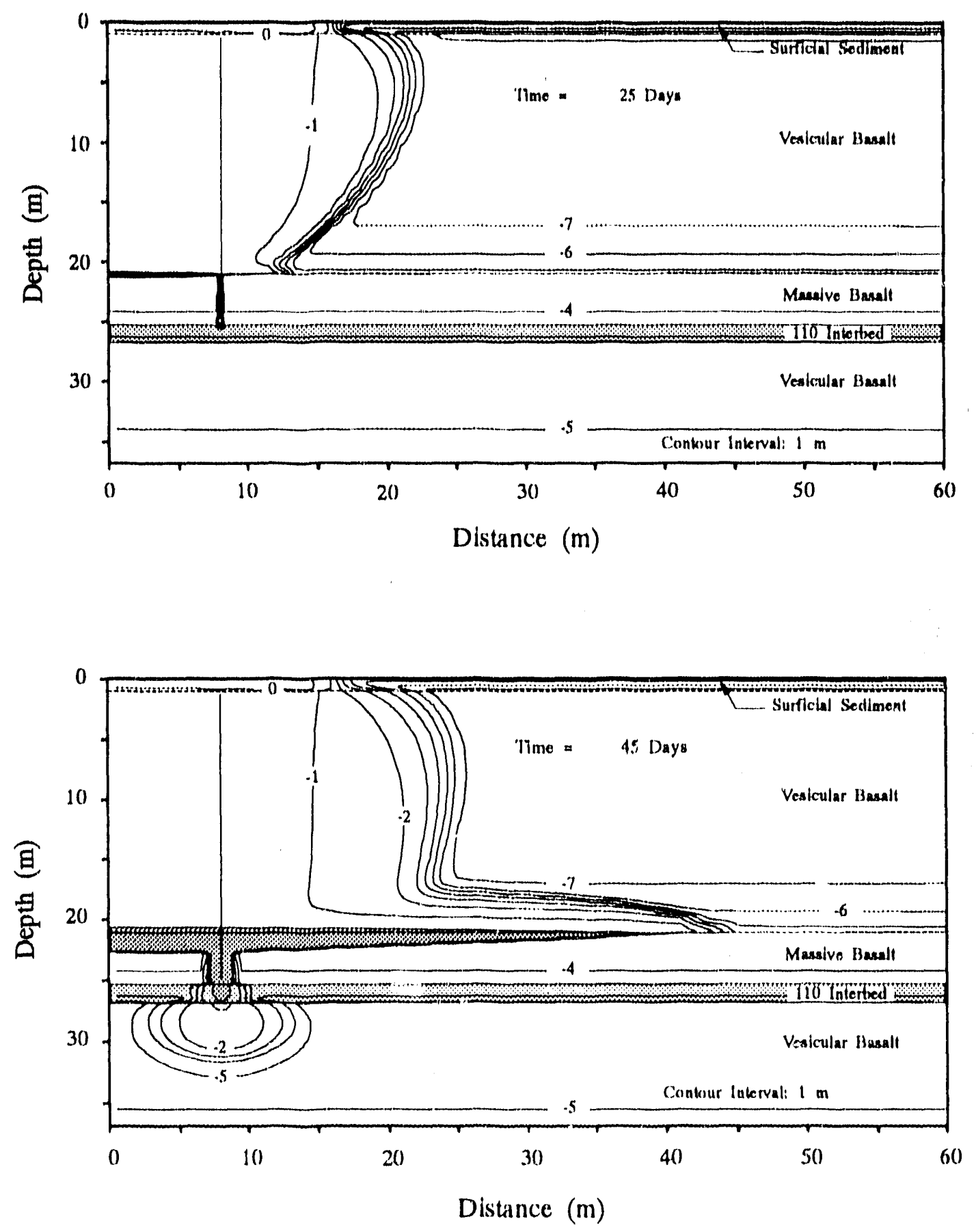

Figure 12. Fractured Case - Pressure Heads at 25 and 45 days 
This simulation also had to be truncated at 45 days for two rensons. First, 45 days was the last comparable simulation time from the base case simulation. And second, the fixed pressure head at the bottom boundary would begin to artificially influence the simulation soon after 45 days. The effect of the fracture can also be observed in another way. By comparing the lateral extent of the perched water at 45 days between the base case and the fracture simulations, it can be seen that the perched water body extends farther in the case without the fractures. Some water has escaped down the fracture in the second case and is no longer available as a driving force for the perched water spreading.

As a result of including the fracture in the simulation, the wetting front was able to move below the $110 \mathrm{ft}$ interbed in 45 days. The wetting front at 45 days in the base case was still "creeping" through the massive basalt. This position of the wetting front in the base case is partially a result of the low conductivity assumed for the massive basalt. But even if only highly conductive vesicular basalt was used (in place of the massive basalt), the wetting front would have likely have perched on the $110 \mathrm{ft}$ interbed and would work its way slowly through the lower conductivity sediment. The wetting front most likely would not have made it past the $110 \mathrm{ft}$ interbed as it did in the fracture simulation. 


\subsection{WATER TRAVEL-TIME PREDICTIONS}

\subsection{INTRODUCTION}

Available hydrogeologic data (Knutson et al., 1992; Anderson and Lewis, 1989) indicate that the geologic setting beneath the RWMC is relatively complex and composed of heterogeneous and anisotropic strata. In this setting, hydraulic properties often vary dramatically from point to point. As a result of this spatial variability, there are a wide spectrum of fast and slow flow paths that percolating water may follow. Consequently, a deterministic or single value calculations of water travel-time is not meaningful.

In order to predict water travel-times in such setting, probabilistic techniques (Freeze, 1975, Yeh, 1989) must be used to compute the distribution of flow paths and travel-times. These techniques are well accepted and commonly applied in performance assessments of radioactive waste disposal sites (Clifton, et al., 1983, Polmann, et al., 1988, Buxton, 1989). Moreover, these techniques are preferred in judging compliance with regulatory limits because they are more realistic and defensible.

To estimate the statistical distributions of water travel-times for the RWMC, Monte Carlo simulations were performed using a one-dimensional, variably saturated flow model. In this simulation approach, a set of random fields are generated to provide realistic representations of:

o net infiltration rate,

o saturated hydraulic conductivity, and

$o$ the thicknesses of the surficial sediments, sedimentary interbeds, and individual basalt flows.

For each random field generated by Monte Carlo sampling, the one-dimensional, variably-saturated flow equation is solved to obtain a realization of the pressure head profile. From this profile and the hydraulic properties, water travel-time is computed from the path length and average fluid velocity. This process is repeated for a large number of realizations or trials until the statis:ical distribution of water travel-times is well defined, $i, p .$. convergence of the mean and variance. Additional details on the Monte Car $6 c^{2}$ sinulation technique are presented in Nguyen, et al. (1992). 


\subsection{PARAMETERIZATION OF HYDRAULIC PROPERTIES}

Large data sets collected were in recent characterization efforts at the RWMC (Knutson et al., 1992: McElroy and Hubbell, 1990) that lend themselves to statistical analysis. In fact, statistical distributions have been developed for a number of hydrogeologic properties, including hydraulic conductivity. Lee (1990), for example, fit various statistical distributions to permeability data for both the sediments and the basalt flows.

For the present study, the derived permeability distributions for the surficial sediments and the interbeds were used (see Appendix II). Permeability data for basalt were compiled by Knutson et al. (1990) for two predominant basalt types, massive and vesicular. Using the available permeability data, empirical distributions were derived for saturated hydraulic conductivity.

Other hydraulic properties such as effective porosity, moisture characteristic curve, and specific storage were treated as deterministic quantities. Values were assigned to these hydraulic properties that were consistent with available field and laboratory data.

\subsection{STRATIGRAPHY}

Because of the large variability of the strata thicknesses and elevations at the RWMC, they were treated as random fields in the model. Knutson et al., (1992) developed statistical representations for the thickness of basalt flows in the subsurface at the RWMC. For an individual basalt flow, statistical representations included overall flow thickness as well as thicknesses of basalt flow components, i.e., rubble, top vesicular, middle massive, and bottom vesicular zones. The vertical component of the Knutson et al. (1992) statistical description was utilized for creating the one-dimensional random fields.

Anderson and Lewis (1989) compiled information on interbed thicknesses and elevations from 35 wells at the RWMC. The reported thickness of the interbeds were used to create empirical distributions. The top elevations of the interbeds were analyzed to determine acceptable ranges of elevations for the two principal interbeds. These acceptable ranges were used to constrain the random field for the subsurface geometry. The statistical representation of the surficial sediment thickness was assumed to be a uniform distribution with values ranging between 0.5 and $3.0 \mathrm{ft}$. This statistical representation was also used for the sediment layer below the waste pit. 
Realistic representations of the stratigraphy were generated by combining the uniform distribution for the surficial sediments, the statistical information for the individual basalt flows, and the empirical distributions for the interbed thicknesses and elevations. An example of the statistically generated hydraulic conductivity profile for one random field is shown in Figure 13. As a result of including variable flow thicknesses, the total number of layers in each realization varied in each random field. The random stratigraphy varied from 80 to 110 layers. Each stratigraphy always consisted of a surficial sediment layer, a $110 \mathrm{ft}$ interbed layer, and a $240 \mathrm{ft}$ interbed layer.

\subsection{INITIAL AND BOUNDARY CONDITIONS}

The boundary conditions for each of the Monte Carlo simulations consisted of fixing the bottom of the column at a fully saturated condition corresponding to the water table and assigning a constant flux at the top. The assigned flux was treated as a random variable with a uniform distribution from 1.0 to $10.0 \mathrm{~cm} /$ year. This range roughly corresponds to reasonable estimates of the net yearly infiltration at the RWMC determined in the infiltration study discussed previously. The initial conditions for each realization were obtained by estimating the head using the prescribed infiltration for that realization and assuming unit gradient conditions.

\subsection{STATISTICAL DISTRIBUTION OF WATER TRAVEL-TIMES}

Monte Carlo simulations of variably saturated flow were performed for a total of 1881 realizations, or trials. The water travel-times were computed for each trial and the results tabulated. The histogram of computed water travel-times is presented in Figure 14. Convergence of the Monte Carlo simulation process was determined by testing the convergence of the mean and standard deviations. The convergence of these statistical parameters is shown in Table 4 as a function of the number of realizations. 

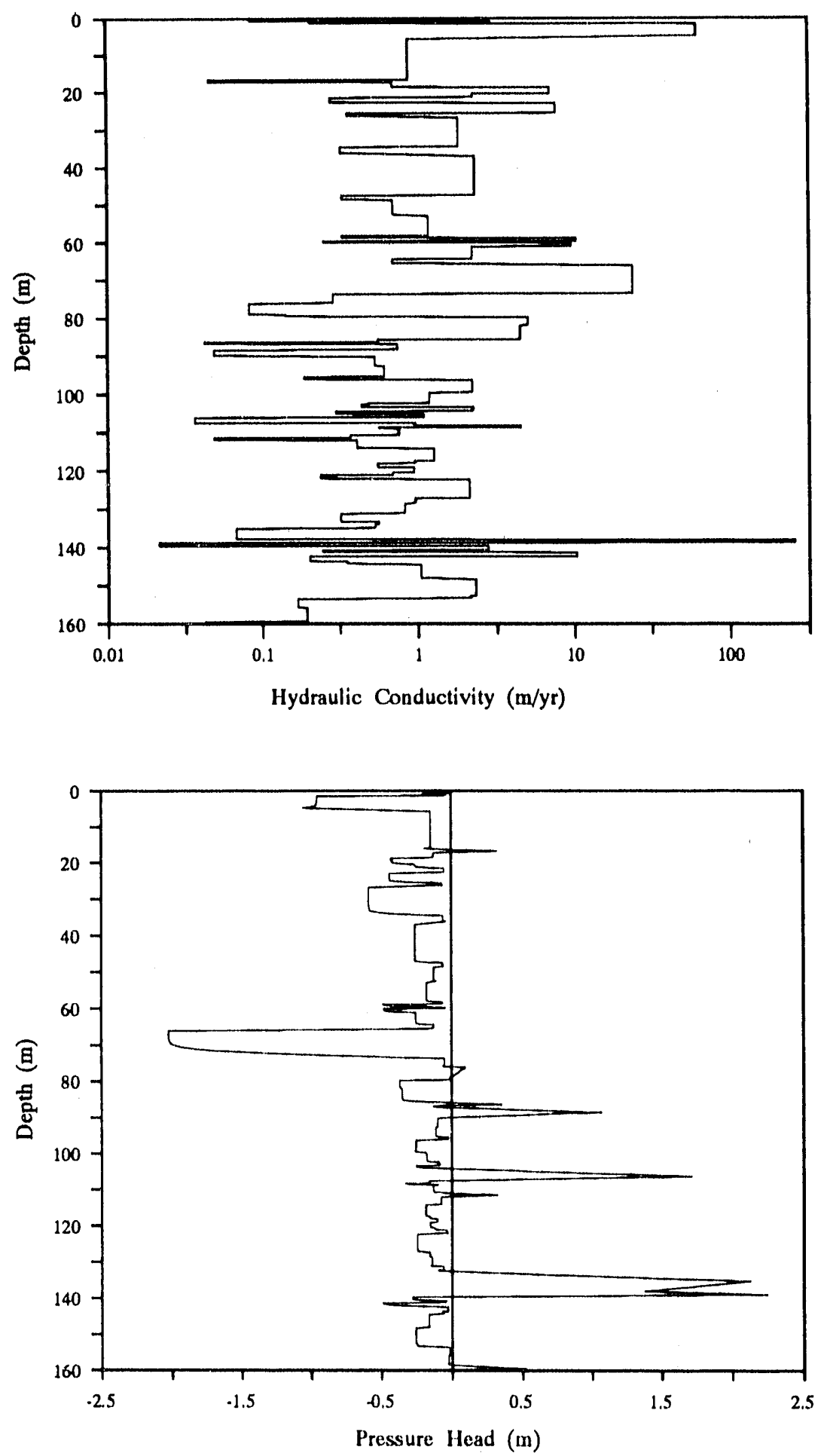

Figure 13. Conductivity and Pressure Profiles for a Random Trial 
As can be noted from Figure 14, the travel-times are approximately log-normally distributed, which indicate a wide range of fast and slow flow paths through the vadose zone. The following statistics were computed from the distribution:

o geometric mean travel-time: 610 yrs

o median travel-time: 547 yrs

o standard deviation: 397 yrs

Because the travel-time distribution is not exactly log-normal, the median travel-time is not equal to the geometric mean.

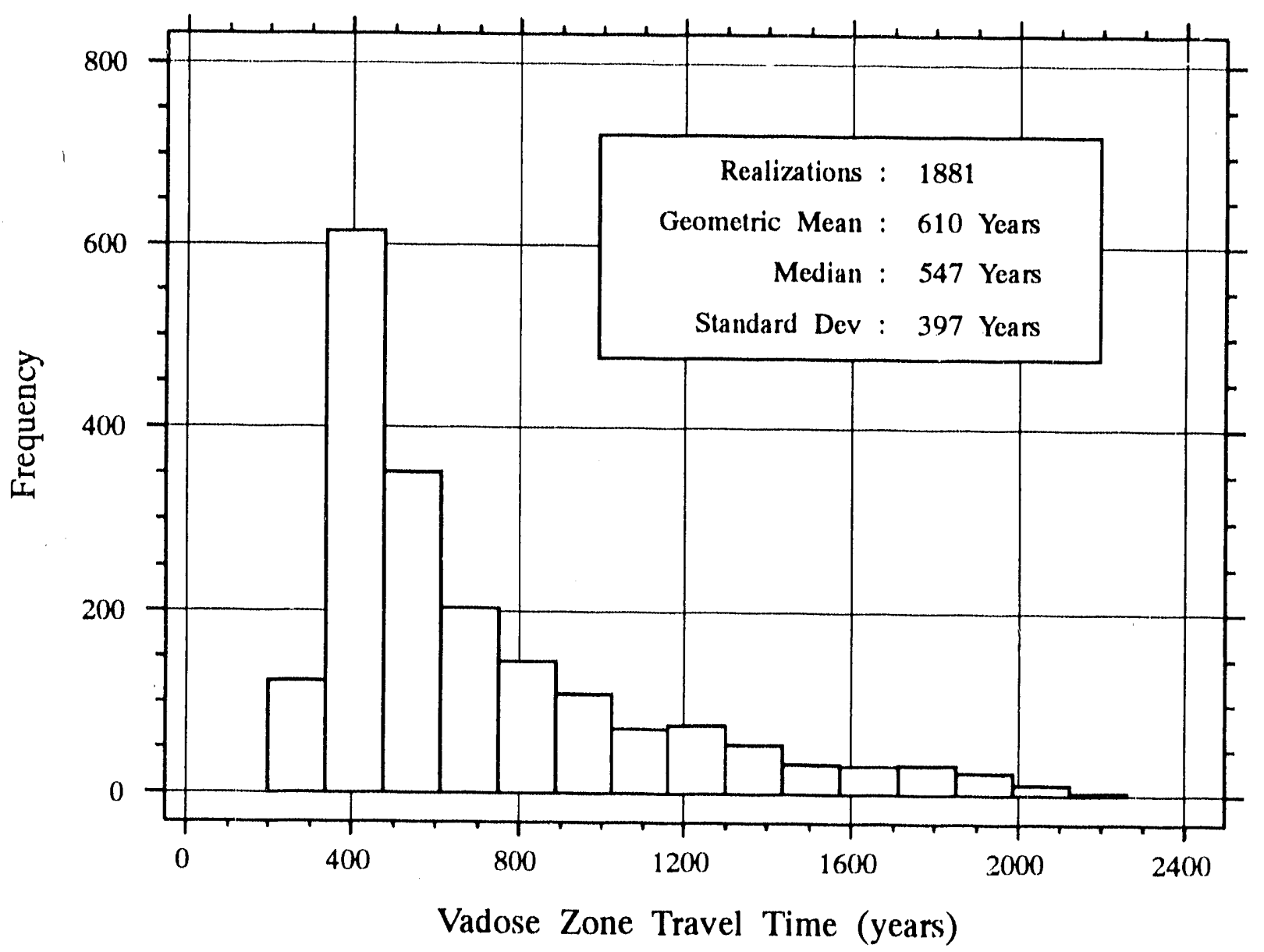

Figure 14. Vadose Zone Water Travel-Time Histogram 
Table 4. Convergence of Travel-Time Mean and Standard Deviation

Number of

Arithmetic Mean

Standard Deviation

Realizations

(years)

(years)

\begin{tabular}{lll}
\hline 100 & 748 & 386 \\
300 & 694 & 383 \\
500 & 689 & 387 \\
700 & 691 & 386 \\
900 & 697 & 399 \\
1100 & 693 & 392 \\
1300 & 691 & 392 \\
1500 & 688 & 391 \\
1700 & 692 & 396 \\
1881 & 696 & 397 \\
\hline
\end{tabular}

It is important to state that the assumption of one-dimensional flow may be non-conservative with respect to the mean and median values. In one-dimensional simulations, water is forced to flow through low permeability layers. In the real system, however, more conductive flow paths may exist in the horizontal direction. This is point is illustrated in the steady-state pressure profile shown in Figure 13. Perched water zones, or regions of positive pressure, develop at certain depths, particularly at $140 \mathrm{~m}$, which corresponds to a relatively low conductivity.

A cumulative probability distribution of travel-times was developed by integrating and normalizing the frequency histogram. This result is presented in Figure 15. From this curve, it possible to estimate exceedence probabilities for given water travel-times. For example, the curve indicates that probability of water travel-times $\left(t_{w}\right)$ exceeding $300 \mathrm{yrs}$, i.e., $P\left[t_{w}>300\right]=.99$. This means that a mobile contaminant moving with the water, i.e., nonsorbing, would have a 99 percent probability of following a flow path with a travel-time of greater than 300 years, to the water table. 


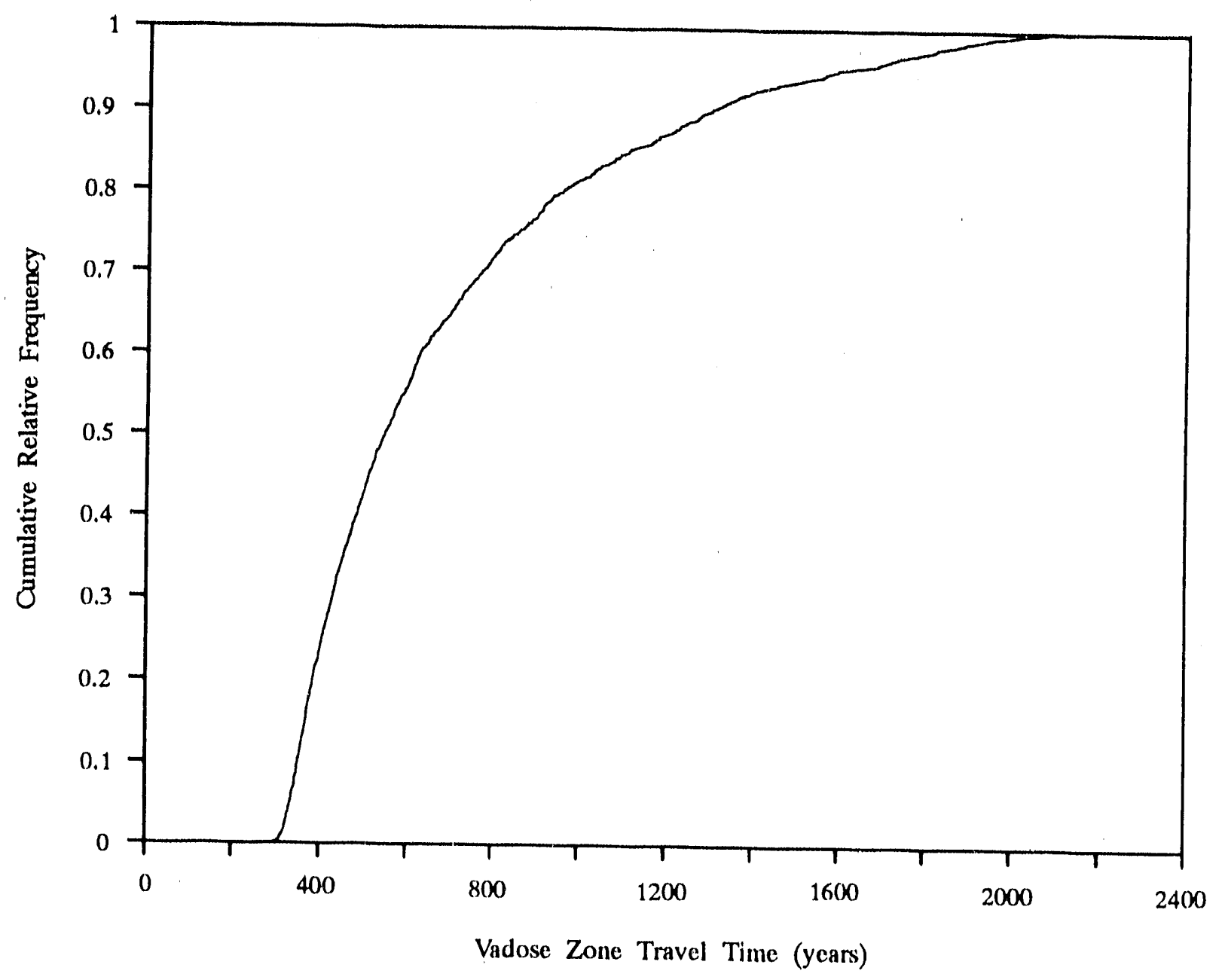

Figure 15. Cumulative Distribution Function for Water Travel-Times 


\subsection{PRELIMINARY FINDINGS AND RECOMMENDATIONS}

A modeling study was conducted for the purpose of gaining insight to the nature of water flow in the vadose zone beneath the Radioactive Waste Management Complex (RWMC). The modeling study focused on three specific hydrologic aspects:

0 analysis of the infiltration rates,

0 evaluation of past flooding of Pit 10 , and

o estimation of the statistical distribution of water travel-times.

These aspects are important to understanding how contaminants may be moving through the vadose zone.

The information presented in this report will be used in future performance assessments of the RWMC conducted for the purposes of: (1) evaluating compliance with the performance objectives of DOE Order 5820.2A, (2) comparing alternatives for final disposition of the wastes and (3) supporting studies associated with the CERCLA and RCRA Remedial Investigation/Feasibility (RI/FS) process.

\subsection{ANALYSIS OF INFILTRATION RATES}

Water infiltration into the surficial sediments of the RWMC is a process of paramount importance because it directly affects the rate of contaminant dissolution, release and migration. Because infiltration rate is a function of many factors (i.e., meteorologic conditions, soil texture and hydraulic properties, degree of plant cover and surface topography), it likely varies widely across the site. At present there is very limited and mostly indirect evidence on infiltration at the RWMC site. For example, a recent tracer study conducted outside of the Subsurface Disposal Area (SDA) by the USGS (NAS, 1990) indicated an average infiltration rate of $10.2 \mathrm{~cm} / \mathrm{yr}(4 \mathrm{in} / \mathrm{yr})$.

To develop a reasonable bound on the average annual infiltration rate for the SDA, computer simulations of soil-moisture movement in the surficial sediments were performed. The simulations considered two specific cases, infiltration in: (1) undisturbed sediments and (2) disturbed sediments (i.e., pit and trench covers). In both cases, infiltration was assumed to occur as an areally diffuse process. A water balance approach was used to simulate the 
infiltration process as a function of meteorologic conditions, Insitu soll-molsture conditions and hydraulic properties. Site meteorologic data for two time perlods were used, namely 1955-1970 and 1982-1990.

Overall, the simulations of the two time periods indicate that soil-molsture tends to cycle in the upper portion of the surficial sediments. This upward and downward movement of soil-moisture occurs in response to precipitation events and extended dry periods when evapotranspiration is dominant. Below this dynamic moisture cycling zone, the water percolation rate varies very gradually over an annual period. The main observations suggested by the simulation results are:

o the dynamic moisture movement occurred in the upper meter of sediments.

0 the maximum moisture-flux at the land surface was estimated to be about $7 \mathrm{~cm} / \mathrm{yr}$ $(2.8 \mathrm{in} / \mathrm{yr})$ or roughly $30 \%$ of the average annual precipitation.

o the net infiltration computed for the disturbed and undisturbed sediments were very similar.

With regard to future performance assessments, the water balance computations suggest that conservative analyses can be performed by assuming net infiltration rates of $10 \mathrm{~cm} / \mathrm{yr}$ or greater. However, higher infiltration rates probably occur in: (1) pit and trench covers where subsidence has occurred, (2) the drainage ditches and depressions where snow or water accumulate, and (3) areas where the sediments are composed of sands.

\subsection{EVALUATION OF PIT 10 FLOODING}

It is generally relieved that the past flooding of the RWMC may have played a significant role in mediating radionuclide migration through the vadose zone. Of the three occurrences of flooding at the RWMC, the 1969 flood was the most extensive. It has been estimated (Vigil, 1988) that during this flood more than eleven million gallons of water passed through pits 8,9 and 10 . Because of its larger extent, Pit 10 accounted for about 80 percent of this estimated volume of water. Computer simulations were performed of the Pit 10 flooding to gain insight into the possible significance of the flooding.

Simulations of the Pit 10 flooding were performed for two scenarios. In the first scenario, the hydrogeologic setting was idealized as homogeneous and anisotropic rock strata with the effects of fractures accounted for in an average sense, i.e., equivalent porous 
medium. The second scenarlo used a similar representation of the strata but included a large, vertical, cross-cutting fracture. Water flow simulations for these two scenarios were performed to estimate the rate of wetting front advancement and the degree of horizontal spreading.

In general, the simulation results suggest that the flooded pit drained gradually into the vadose zone over a period of months. A large and well defined wetting front was probably created by the flooding. The simulations indicate that the wetting front moved relatively rapidly through the vadose zone, impinging on a low permeability basalt flow above the 110 $\mathrm{ft}$ interbed. At this basalt flow, perching of the water occurs with the wetting front then moving predominantly in the lateral direction. The primary observations from the water flow simulations are:

o The wetting front created by the flooding of Pit 10 could have reached the vicinity of the $110 \mathrm{ft}$ interbed in about one month time.

o A low permeabllity basalt flow could produce considerable lateral spread of the wetting front.

o Vertical, cross-cutting, unfilled fractures are potentially very efficient conduits that can move water rapidly through the vadose zone.

These findings support the conjecture that past flooding events may have been a major factor causing migration of nonsorbing, dissolved contaminants and/or contaminants in colloidal phase.

\subsection{ESTIMATION OF WATER TRAVEL-TIMES}

Water travel-time or residence time is a fundamental, arid typically conservative, indicator of how well the geologic setting is able to confine mobile contaminants. Travel-times that are long relative to contaminant half-lives, for example, indicates that the contaminants will decay away prior to reaching the accessible environment. To assess the performance of disposal facilities at the RWMC, estimates of the water travel-iimes from the pits and trenches to the water table are required.

Because of the complexities of the geologic setting and the large variation in hydraulic properties, a deterministic or single value calculation of the water travel-time is not meaningful. As a result, a probabilistic approach, referred to as Monte Carlo simulation, was 
applled to estimate the water travel-fime distribution for the RWMC. Statistical distributions of the annual average infiltration rate, staturated hydraulic conductivities and strata thickness were used in these computations. These computations ylelded the following results

o Water travelatimes through the vadose zone are lognonomally distributed.

o The geometric-mean water travel time through the vadose zone is about 610 years, which corresponds to an average linear velocity of about $0.3 \mathrm{~m} / \mathrm{yr}$.

The fact that the water travel-times are lognormally distributed indlcates a wide range of fast and slow flow paths through the vadose zone. From the computed cumulative probability distribution, it was estimated that there is a greater than $99 \%$ probability of water travel-times $\left(t_{w}\right)$ exceeding 300 yrs, i.e., $P\left[t_{w}>300\right]=.99$. This means that a mobile contaminant moving with the water, l.e., nonsorbing, would have a 90 percent probability of following a flow path with a travel-time of greater than 300 years, to the water table.

\subsection{RECOMMENDATIONS}

Fulfillment of the DOE goals for radiological safety, environmental restoration and facility operation programs at the RWMC will require continued study of the subsurface environment. A sound technical understanding of the hydrogeology and its relation to waste migration can be developed through a coordinated effort of site characterization, l.e., data collection, predictive modeling and independent peer review. One of the principal benefits of such an effort would be the ability to anticipate and mitigate potential waste migration problems.

With regards to site characterization activities, it is recommended that additional data be compiled on basic hydraulic parameters such as:

o characteristic curves (i.e., capillary pressure versus molsture content),

o) saturated hydraulic conductivities,

0 effective porosities.

Because of the large spatial variability of hydraulic conductivities and porosities, sufficient numbers of data points need to be compiled to allow: (1) the definition of their statistical 
distributions and (2) geostatistical interpretation of spatial treads la the major hydrostratigraphic units. Additional data on these parameters needs to be complled for the undisturbed surficial sediments, cover materials, interbeds and basalt strata.

A number of field infiltration/drainage tests, such as that conducted by Kaminsky (1991), are needed to corroborate data from core samples and to evaluate the nature of scale effects on hydraulic propertles. These field tests should performed at various locations in the SDA, with particular emphasis in:

0 areas with new and old cover materials,

o plts and trenches that may have experienced contaninant movement, and

o drainage ditches and other areas of major local recharge.

These tests would provide important data needed to assess the movement of waste from: (1) the pits and trenches and (2) tertiary source locations in the subsurface. In addition, infiltration/drairage/tracer tests should be conducted with the specific goal of providing data for validation of the flow and transport models.

In the area of fluids and contamina:t modeling, technical effort should be direct to:

o parametric, sensitivity and uncertainty modeling studies,

o model validation studies, and

o assessments of potential migration of radionuclides, heavy metals and other carcinogenic materials disposed at the site.

Parametric, sensitivity and uncertainty modeling studles should be conducted to provide guidance for the site characterization activities; in particular, these studies should provide guidance on the adequacy and completeness of data needs. Model validation studies should be undertaken to aid in building confidence in the individual predictive tools. Available data indicate that, in addition to the radioactive waste, significant quantities of heavy metals (eg., mercury, lead, chromium, etc) were disposed at the RWMC; modeling studies should conducted to evaluate the possible rapid movement of these contaminants.

As additional data and knowledge are gained, periodic updates of the performance assessment for the water pathway should be conducted to: (1) evaluate the potential 
movement of radionuclides in both dissolved and colloidal phases, (2) evaluate the potential movement of specific hazardous waste components disposed at the SDA and (3) assess compliance of the site with radiologic requirements of DOE 582().2A. 


\section{ACKNOWLEITGMN'IS}

The authors wish to thank a number of individuals that contributed to this project. First and foremost, the authors thank Ms. M. Beth Sussman, Technology Programs, for her assistance during the conduct of this study. The authors acknowledge the contributions of Mr. Cary Smith, Geosciences Group, for his initial effort in preparing input data decks for the various computer codes. The authors also thank Mr. Tony $\mathrm{R}$. Moser for his assistance with preparation of numerous graphs and illustrations. 


\section{REFERENCES}

Anderson, S. R. and D. B. Lewis, "Stratigraphy of the Unsaturated Zone at the Radioactis" Waste Management Complex, Idaho National Engineering Laboratory, Idaho," Report 8904065, U.S. Geological Survey, Idaho Fal'.s, ID (1989).

Baca, R. G., I. P. King, W. R. Norton, "Finite Element Models for Simultaneous Heat and Moisture Transport in Unsaturated Soils," Proceedings of the Second International Conference on Finite Elements in Water Resources, Imperial College, Pentech Press, London (1978).

Baca, R. G., J. C. Walton, and A. S. Rood, "Organic Contaminant Release from a Mixed Waste Disposal Site: Analysis of Vapor Transport through the Vadose Zone and Site Remediation," Proceedings of Tenth Annual DOE Low-Level Waste Management Conference, Denver, CO (1988).

Barraclough, J. T., J. B. Robertson, and V. J. Jauzer, "Hydrology of the Solid Waste Burial Ground, as Related to the Potential Migration of Radionuclides," U. S. Geological Survey, Open File Report 76-471, Idaho National Engineering Laboratory (1976).

Bishop, C. W., "Hydraulic Properties of Vesicular Basalt," MS Thesis, University of Arizona, Tucson, AZ (1991).

Borghese, J. V. "Hydraulic Characteristics of Soil Cover, Subsurface Disposal Area, Idaho National Engineering Laboratory," MS Thesis, University of Idaho, Moscow, ID (1988)

Buxton, B. E. (Editor), Geostatistical, Sensitivity, and Uncertainty Methods for Ground-Water Flow and Radionuclide Transport Modeling, Conference Proceeding, CONF-870971, Battelle Press, Columbus, OH (1989).

Campbell, G. S., Soil Physics with Basic, Elsevier Publishing Company, New York, NY (1985).

Case, M. J., S. J. Maheras, M. A. Mckenzie-Carter, M. E. Sussman and P. Voilleque, "Radioactive Management Complex Performance Assessment," EGG-WM-8773, EG\&G Idaho, Inc., Idaho Falls, ID (1989). 
Clawson, K. L., et al., "Climatology of the Idaho National Engineering Laboratory," 2nd Edition, DOE/ID-12118, U.S. Department of Energy, Idaho Falls, ID (1989).

Clifton, P. M., R. G. Baca, R. C. Arnett, "Stochastic Analysis of Groundwater Traveltimes for Long-Term Repository Performance Assessment," in the Proceedings of the Materials Research Society Symposium - Scientific Basis for Nuclear Waste Management, Boston (1983).

Corey, A. T., Mechanics of Heterogeneous Fluids in Porous Media, Water Resources Publications, Fort Collins, CO (1977).

Davis, L. C., Pittman, J. R., "Hydrological, Meteorological, and Geohydrological Data for an Unsaturated Zone Study Near the Radioactive Waste Management Complex, Idaho National Engineering Laboratory, Idaho--1987", U.S. Geological Survey INEL, U.S.G.S. Report 90-114, (1990).

DOE (U. S. Department of Energy), "Environmental and Other Evaluations of Alternatives for Management of Defense Transuranic Waste at the Idaho National Engineering Laboratory", DOE/IDO-10103, Vol. 1\&2, (1982).

DOE (U. S. Department of Energy), "A Plan for Studies of Subsurface Radionuclide Migration at the Radioactive Waste Management Complex of the Idaho National Engineering Laboratory," DOE/IDO-10116, Vol 1\&2, (1983).

EG\&G (EG\&G Idaho, Inc.), "Radioactive Waste Management Complex (RWMC) Subsurface Investigations Program Peer Review Report," EGG-BEG-8071, EG\&G Idaho, Inc. Idaho Falls, ID (1988).

EG\&G (EG\&G Idaho, Inc.), "Methodology for Compliance with DOE Order 5820.2A Chapter III: Management of Low-Level Waste," DOE/LLW-75T, prepared by the National Low-Level Waste Management Program, EG\&G Idaho, Inc., Idaho Falls, ID (1989).

Fayer, M. J. and T. L. Jones, "UNSAT-H Version 2.0: Unsaturated Soil Water and Heat Flow Model," PNL-6779, Pacific Northwest Laboratory, Richland, WA (1990). 
Freeze, R. A., "A Stochastic-conceptual Analysis of One-Dimensional Groundwater Flow in Nonuniform Homogeneous Media," Water Resources Research, Vol. 11, No. 5, pp. 725-741 (1975).

Freeze, R. A. and J. A. Cherry, Groundwater, Prentice-Hall, Inc., Englewood Cliffs, NJ (1979).

Hanks, R. J. and L. G. King, "Irrigation Management for Control of Quality of Irrigation Return Flow," EPA R2-73-265, U. S. Environmental Protection Agency, Washington, DC (1973).

Hillel, D., Soil and Water, Physical Principles and Processes, Academic Press, New York, NY (1971).

Hubbell, J. M., "Perched Ground Water at the Radioactive Waste Management Complex of the Idaho National Engineering Laboratory, EGG-ER-8779, EG\&G Idaho, Inc. Idaho Falls, ID (1990).

Humphrey, T. G., T. H. Smith, and M. C. Pope, "Projected Subsurface Migration of Radionuclides from Buried Idaho National Engineering Laboratory Transuranic Waste," Nuclear Technology, Vol. 58., pp. 136-149 (1982).

Kaminsky, J. F., "Insitu Characterization of Unsaturated Hydraulic Properties of Surficial Sediments adjacent to the Radioactive Waste Management Complex, Idaho National Engineering Laboratory, Idaho," MS Thesis, Idaho State University, Pocatello, ID (1991).

Knutson, C. F., K. A. McCormick, R. P. Smith, W. R. Hackett, J. P. O'Brien and J. C. Crocker, "FY 89 Report - RWMC Vadose Zone Basalt Characterization," EGG-WM-8949, EG\&G Idaho, Inc., Idaho Falls, ID (1990).

Knutson, C. F., K. A., McCormick, J. C. Crocker, M. A. Glenn, and M. L. Fisher, "3D RWMC Vadose Zone Model (including FY 89-90 Basalt Characterization Results) Informal Report", EGG-GEO-9943, EG\&G Idaho, Inc., Idaho Falls, ID (1992 expected). 
Laney, P. T., S. C. Minkin, R. G. Baca, D. L. McElroy, D. L. Hubbell, J. M. Hubbell, L. C. Hull, B. F. Russell, G. J. Stormberg, and J. R. Pittman, "Annual Progress Report: FY-1987--Subsurface Investigations Program at the Radioactive Waste Management Complex of the Idaho National Engineering Laboratory," DOE/ID-10183, prepared by EG\&G Idaho, Inc. Idaho Falls, ID (1988).

Lee, C. B., "Summary of Statistical Analysis of Permeability, Porosity and Bulk Density at the RWMC," Interoffice Correspondence, $C B L-01-90$, EG\&G Idaho, Inc, Idaho Falls, ID (1990).

McElroy, D. L., "Vadose Zone Monitoring at the Radioactive Waste Management Complex at the Idaho National Engineering Laboratory 1985-1989", EGG-WM-9299, EG\&G Idaho Inc., Idaho Falls, ID (1990).

McElroy, D. L. and J. M. Hubbell, "Hydrologic and Physical Properties of Sediments at the Radioactive Waste Management Complex", EGG-BG-9147, EG\&G Idaho Inc., Idaho Falls, ID (1990).

Mualam, Y., "A New Model for Predicting the Hydraulic Conductivity of Unsaturated Porous Media," Water Resources Research, Vol. 12, No. 3, pp. 513-522 (1976).

Mizell, S. A. and L. C. Hull, "Preliminary Modeling of Radionuclide Migration through the Subsurface at the INEL Radioactive Waste Management Complex Using the Unsaturated Flow and Transport Model UNSAT," RE-PB-83-038, EG\&G Idaho, Inc., Idaho Falls, ID (1983).

NAS (National Academy of Sciences), "National Academy of Sciences," presentation prepared by EG\&G's Environmental Restoration Program, EG\&G Idaho, Inc., Idaho Falls, ID (1990).

NOAA (National Oceanic and Atmospheric Administration), "TD-3210 Summary of Day First Order", National Climatic Data Center Federal Building, Asheville, NC (1990).

Pittman, J. R., "Hydrological and Meteorological Data for an Unsaturated Zone Study near the Radioactive Waste Management Complex, Idaho National Engineering Laboratory, Idaho-1985-86", Report 89-74, U.S. Geological Survey, Idaho Falls, ID (1989). 
Polmann, D. J., E. G. Vomvoris, D. McLaughlin, E. M. Hammick and L. W. Gelhar, "Application of Stochastic Methods to the Simulation of Large-Scale Unsaturated Flow and Transport," NUREG/CR-5094, prepared by Massachusetts Institute of Technology for the U.S. Nuclear Regulatory Commission, Washington, DC (1988).

Pope, M. C. and H. W. Reno, "Modeling Radionuclide Transport in the Unsaturated Zone Beneath the Radioactive Waste Management Complex," (Draft Report), EG\&G Idaho, Inc., Idaho Falls, ID (1982).

RAE (Rogers and Associates Engineering), "DOE Site Performance Assessment Activities," DOE/LLW-99, prepared for EG\&G Idaho, Inc., Idaho Falls, ID (1990).

Rasmussen, T. C., D. D. Evans, and T. J. Nicholson, "Unsaturated Flow and Transport Through Fractured Rock Related to High-Level Waste Repositories, Final Report Phase II," NUREG/CR-4655, prepared by the Department of Hydrology and Water Resources, University of Arizona, Tucson, AZ (1987).

Rawson, S. A., J. C. Walton, and R. G. Baca, "Migration of Actinides from a Transuranic Waste Disposal Site in the Vadose Zone," Radiochimica Acta, 52/53, pp. 477-486 (1991).

Richardson, C. W., and D. A. Wright, "WGEN: A Model for Generating Daily Weather Variables", United States Department of Agriculture (Agriculture Research Service), USDA Report PB85-107100 (1984).

Rightmire, C. T. and B. D. Lewis, "Hydrology and geochemistry of the unsaturated zone, Radioactive Waste Management Complex, Idaho National Engineering Laboratory, Idaho," Report 87-4198, U. S. Geological Survey, Idaho Falls, ID (1987).

Robertson, J. B., R. Schoen, J. T. Barraclough, "The Influence of Liquid Waste Disposal on the Geochemistry of Water at the National Reactor Testing Station, Idaho: 1952-1970," U.S.G.S. Open-File Report IDO-22053, Idaho Falls, ID (1974).

Robertson, J. B., "Digital Modeling of Radioactive and Chemical Waste Transport in the Snake River Plain Aquifer at the National Reactor Testing Station, Idaho, "U.S.G.S. Open-File Report IDO-22054, Idaho Falls, ID (1974). 
Robertson, J. B., "Numerical Modeling of Subsurface Radioactive Solute Transport from Waste-Seepage Ponds at the Idaho National Laboratory," U.S.G.S. Open-File Report IDO-22057, Idaho Falls, ID (1977).

Runchal, A. K. and B. Sagar, "PORFLOW: A Model for Fluid Flow, Heat, and Mass Transfort in Multifluid, Multiphase Fractured or Porous Media: User's Manual Version 2.30," Analytic and Computational Research, Inc., Los Angeles, CA (1990).

Russell, B. F., J. M. Hubbell, and T. G. Humphrey, "Subsurface Investigations at the Radioactive Waste Management Complex of the Idaho National Engineering Laboratory," in Waste Management '87, Tucson, AZ (1987).

Schmalz, B. L. "Injection of Gas into the Lithosphere at the National Reactor Testing Station, IDO-12069, U. S. Atomic Energy Commission, Idaho Falls, ID (1969)

Smith, L. and R. A. Freeze, 1979, "Stochastic Analysis of Steady-State Groundwater Flow in Bounded Domain, 1. One-Dimensional Simulations, Water Resources Research, Vol. 15, No. 3, pp. $521-528$ (1979).

Snow, D. T., "Anisotropic Permeability of Fracture Media," Water Resources Research, Vol. 5, No. 6, pp. 1273-1289 (1969).

TerraTek, "Special Core Analysis of Basalt Samples, TR 89-27, prepared by TerraTek Laboratory, Salt Lake City, UT (1988).

van Genuchten, M. T., "Calculating the Unsaturated Hydraulic Conductivity with a New Closed-Form Analytical Model," Report 78-WR-08, Water Resources Program, Princeton University, Princeton, NJ (1978).

van Genuchten, M. T., "A Closed-Form Equation for Predicting the Hydraulic Conductivity of Unsaturated Soils," Soil Science Society of America Journal, Vol. 44, pp. 892-898, (1980).

Vigil, M. J., "Estimate of Water Pits During Flooding Events," EDF-BWP-12, EG\&G Idaho, Inc., Idaho Falls, ID (1988).

Vigil, M. J., "Subsurface Disposal Area (SDA) Waste Identification (1952-1970 Emphasis)", EGG-WM-8727, EG\&G Idaho Inc., Idaho Falls, ID (1989). 
Wang, J. S. Y., and T. N. Narasimhan, "Hydrologic Mechanisms Governing Fluid Flow in a Partially Saturated, Fractured, Porous Medium," Water Resources Research, Vol. 21, No. 12, pp. 1861-1874 (1985).

Yeh, T.-C. J., "One-Dimensional Steady-State Infiltration in Heterogeneous Soils," Water Resources Research, Vol. 25, No. 10, pp. 2149-2158 (1989). 


\section{GLOSSARY}

Aquifer

Benchmarking

Calibration

\section{CERCLA}

Computer code

Hazardous wastes
A saturated, permeable geologic unit that can transmit significant quantities of water under ordinary hydraulic gradients.

Computational testing involving code-to-code comparisons in which simulations are used to provide assurance that the code calculations are consistent with results of other established codes.

The process of synchronizing the cause and effect relationships described in a computer model with the observed behavior of a real physical system or process. This process involves adjusting the uncertain model input parameters such that the computer simulation mimics, in a best fit sense, the dynamics of the physical system.

Comprehensive Environmental Response, Compensation, and Liability Act. A regulatory statute the establishes remedies and allocates responsibilities for correcting problems at abandoned and inactive waste sites.

A computer program written in FORTRAN (or any other symbolic language) that performs a numerical solution of a set of governing equations and produces calculations of state variables (i.e., temperature, hydraulic head, concentration, etc.) over space and/or time.

Wastes designated as chemically or biologically hazardous by Environmental Protection Agency regulations (40 CFR 261). 
Hydrostratigraphic unit

INEL

Infiltration

Low-level waste (radioactive)

Model

Migration

Performance Assessment
A formation, part of a formation, or a group of formations in which there are similar hydrologic characteristics allowing for groupings into aquifers or confining layers.

Idaho National Engineering Laboratory

The flow of water downward from the land surface into and through the upper soil layers.

Radioactive material that other than uranium mine or mill tailings, high-level waste, spent fuel, transuranic waste, or by-product material as defined in Section $11 \mathrm{a}(2)$ of the Atomic Energy Act of 1954. Wastes that contain radionuclides emitting primarily beta and/or gamma radiation and less than 100 nanocuries per gram of transuranic elements.

A conceptual description and the associated mathematical representation of a system, subsystem, component or condition. A model describes the relationship between state variables as a function of time, space, initial and/or boundary conditions.

Movement of contaminants from the place where disposed waste was initially emplaced, generally by groundwater transport.

The analytic process of modeling the behavior of a disposal system and its components under a variety of expected and hypothetical conditions. The modeling is conducted to develop an understanding of the events and processes that might affect the ability of disposal system to limit releases to acceptable levels. 
RCRA

RWMC

Saturated zone

Scenario

Sensitivity analysis

SDA

Transport pathway

Uncertainty analysis
Resource and Recovery Act. A regulatory statue designed to provide cradle to grave management of hazardous waste by imposing management requirements on generators and transporters of hazardous materials and upon owners and operators of treatment, storage and disposal facilities.

Radioactive Waste Management Complex. The INEL's primary waste storage and disposal facility.

That part of the earth's crust beneath the water table in which all voids are filled with water under pressure greater than atmospheric.

A particular chain of hypothetical circumstances that result in loss of contaminant, release and/or transport of contaminants from the disposal site.

A computational exercise performed with a computer code that is aimed at identifying the model inputs that have the most influence on model predictions. Typically involves performing a set of computer simulations and monitoring the change in predictive output per unit change in an input parameter.

Subsurface Disposal Area. An 88 acre area of the Radioactive Waste Management Complex which is used for low-level waste disposal.

A route through which contaminants could migrate and reach the accessible environment.

A computational exercise performed with a computer code that is aimed at identifying the impact of uncertainty in model inputs on the model predictions. 
Vadose zone

Code verification

Model validation

Waste form
Typleally pertormed using a flist order uncertainty or Monte Carlo sampling technique with statlstical representations of model input parameters.

The unsaturated region of soll from land surfice to the top of the water table. Also referred to as the zone of aeration.

Code testing consisting of comparison between the computer code and known analytical solutions. Testing that is aimed at assuring that the correcting performs the computations specified by the numerical algorithm.

Testing process aimed at determining the degree to which a model describes the behavior of a real world situation or process. The testing is performed by comparing model predictions against data from laboratory and/or field experiments.

The radioactive waste materials and any encapsulating or stabilizing matrix. 


\section{APPENDIX I - DESCRIPTIONS OF COMPUTER CODLS}

A set of computer codes were used in this study to model varlous aspects of water flow through the vadose zome beneath the Radionctive Waste Management Complex (RWMC). In particular, the computer codes were used to perform the following: (1) simulate the soll-moisture dynamics and estimate the net infiltration as a function of meteorologic conditions, (2) model the water movement associated with past flooding of the RWMC, and (3) estimate the statistical distribution of water travel-times through the vadose zone.

Specific computer codes used in this study consisted of: UNSAT-H, FLASH, PORFLOW and FLOWMC. All of these codes are maintained under a formal software QA management and configuration management procedure (Baca, 1990). Summary descriptions of these codes are presented below.

\section{UNSAT-H}

\section{Description:}

The UNSAT-H computer code is designed to model dynamic soil-moisture movement through the vadose zone. One -dimensional movement of water in the vertical direction is modeled as a function of the site-specific meteorologic conditions, soll-hydraulic properties and hydraulic boundary conditions. In addition, the code has the capability to account for such processes as

o liquid and vapor water flow

o evapotranspiration

o uptake of water from soil by plants.

One limitation of the code is that it applies strictly to unsaturated flow, i.e., does not handle fully saturated conditions leading to positive pressure heads.

The net infiltration rate for a site can be estimated with the UNSAT-H code by simulating a historical period and monitoring the computed moisture flux at selected depths. The estimated net infiltration rate provides a necessary boundary condition for multidimensional simulations of fluid flow and contaminant transport. 
The code is written in FORTRAN 77 programming language and consists of three distinct modules: (1) DATAINH - a general input file processor, (2) UNSAT-H - the flow simulator and (3) DATAOUT - a general output processor. The UNSAT-H code has a number of unique capabilities and user options. The UNSAT-H source code, which is avallable from PNL, was developed on a VAX minl-computer and therefore uses certain VAX specific features. For this study, the UNSAT-H, version 2.0, source code was generalized so the code would operate on an IBM PC, SUN workstation, and Cray supercomputer.

The UNSAT-H 2.0 code has been verifled against a number of known analytical solutions. The results of the verification testing are documented in Baca and Magnuson (1990). In addition, the code has been benchmarked by making code-to-code comparison for various flow and heat transport simulations (Baca and Magnuson, 1990). A number of hypothetical but realistic test problems were simulated with UNSAT-H and other independent computer codes. The codes used in the benchmarking process were: FEMWATER (Yeh and Ward, 1979), FLASH (Baca 1992), TOUGH (Pruess, 1983), SUTRA (Voss, 1984) and TRACR3D (Travis, 1984).

\section{Computer Requirements:}

For a number of applications, the UNSAT-H will run effectively and efficiently on a PC with a 386 central processor unit $(\mathrm{cpu})$. For those cases with significant hydrostratigraphic complexity and high grid density, the UNSAT-H code will require a minimum of a PC computer with 486 cpu or preferably a scientific workstation. The UNSAT-H, version 2.(), code was developed for the U. S. Department of Energy and is therefore public domain software. Copies of the source code are available from M. J. Fayer, Pacific Northwest Laboratories, Richland, Washington.

\section{Code References:}

Baca, R. G. and S. O. Magnuson, "Independent Verification and Benchmark Testing of the UNSA.T-H Computer Code, Version 2.0", EGG-BEG-8811, Idaho National Engineering Laboratory, Idaho Falls, Id. (199()). 
Fayer, M. J., G. W. Gee, and T. L. Jones, "UNSAT-H Version 1.(): Unsaturated Flow Code Documentation and Applications for the Hanford Site", PNL-5899, Pacific Northwest Laboratory, Richland, WA (1986).

Fayer, M. J. and T. L. Jones, "UNSAT-H Version 2.0: Unsaturated Soil Water and Heat Flow Model", PNL-6779, Pacific Northwest Laboratory, Richland, WA (1990).

\section{ELASH Computer Code}

\section{Description:}

The FLASH computer code (Baca, 1992) was developed to model the unique hydrologic characteristics of the RWMC vadose zone which is composed of fractured-porous basalt strata and interbedded sediments. Development of the code was motivated by the fact many of the available codes were unable to: (1) describe flow in discrete fractures, (2) correctly solve the flow equation with the strongly nonlinear hydraulic properties of the site, and (3) provide convergent solutions for arid site conditions.

The FLASH computer codo is designed to simulate fluld flow and/or heat transport in a variably-saturated, porous continuum with discrete fracture systems. The code solves the time-dependent, two-dimensional forms of the governing equations in either Cartesian or radial coordinate systems. The major processes modeled are:

o liquid and vapor water flow

o fluid flow by capillary, gravity and thermal forces

o heat transport by conduction

The model theory uses a "dual permeability" approach for describing fluid flow in discreti fractures and porous continua. The numerical technique implemented in the code is specifically designed to handle strongly nonlinear problems such as those found in unsaturated flow at arid sites.

A Taylor Weak Statement formulation of the Galerkin finite element technique, in conjunction with a Newton-Raphson iteration algorithm, is used to solve the nonlinear governing equations. The code uses a general algorithm that automatically adjusts the time 
step as necessary to maintain a fixed truncation error. The code accommodates any combination of 3-node line elements, 6-node triangular elements, and 8-node quadrilateral elements.

The code accommodates three types of boundary conditions: (1) fixed pressure head and/or temperature, (2) fluid and/or heat flux and (3) free drainage flow boundary. The code is interfaced with a number of post-processor routines that allow the user to calculate and plot: (1) velocity vectors, (2) streamlines or pathlines, (3) pressure and/or temperature contours. The code is also interfaced with the general contaminant transport code, FLAME.

The FLASH computer code has been extensively verified with analytical solutions and benchmark tested against simulation results obtained with numerous other computer codes such as UNSAT1D (Celia, 1990), UNSAT2D (Celia, 1990), VAM2D (Huyakorn, et ai., 1989), TRACR3D (Travis, 1984), FEMWATER (Yeh and Ward,1979), SUTRA (Voss, 1984) and TOUGH (1979). Results of these testing results are documented in the reports by Baca and Magnuson (1990), Magnuson et al. (1990) and Baca (1992).

\section{Computer Requirements:}

The computer code is written in FORTRAN 90 and is operational on a Cray X-MP $2 / 16$, SUN workstation and IBM PS/2 with extended memory. Practical applications of the FLASH code to realistic flow and transport problems in fracture-porous media require the availability of a high performance PC (i.e., 486), scientific workstation or mainframe computer. The simulations presented in this report were performed on a Cray X/MP supercomputer.

\section{Code References:}

Baca, R. G., "A Finite Element Computer Code for Variably-Saturated Flow in Fractured-Porous Media," (in preparation), EG\&G Idaho, Inc., Idaho Falls, ID (1992).

Baca, R. G. and S. O. Magnuson, "Independent Verification and Benchmark Testing of the UNSAT-H Computer Code, Version 2.0", EGG-BEG-8811, Idaho National Engineering Laboratory, Idaho Falls, Id. (1990).

Magnuson, S. O., R. G. Baca, and A. J. Sondrup, "Independent Verification and Benchmark Testing of the PORFLO-3 Computer Code, Version 1.0", EGG-BG-9175, Idaho National Engineering Laboratory, Idaho Falls, Id. (1990). 


\section{PORFLOW}

\section{Description:}

The PORFLOW computer code (Runchal and Sagar, 1989) was developed for Rockwell Hanford Operations (now Westinghouse Hanford Company) to evaluate hazardous and radioactive waste problems. The computer code is based on numerical solution of the general equations for: (1) time-dependent, nonisothermal porous flow, (2) transport of a reactive solute, and ( 3 ) coupled heat transport.

The governing equations describing these processes are approximated by an integrated finite-difference technique. Both direct and iterative solution approaches are available and can be used to solve the finite-difference equations. Major assumptions of the model formulation are: (1) the fluid is incompressible, (2) fluid flow is independent of the air phase, (3) hydraulic properties are non-hysteretic, (4) the porous medium is rigid, and (5) solute concentrations do not affect the flow properties of the water.

The PORFLOW code has been verified against a number of known analytical solutions. The results of the verification testing are documented in Magnuson et al. (1990). In addition, the code has been benchmarked by making code-to-code comparison for various flow and heat transport simulations (Magnuson et al., 1990). A number of hypothetical but realistic test problems were simulated with PORFLOW and other independent computer codes. The codes used in the benchmarking process were: FEMWATER (Yeh and Ward, 1979), FLASH (Baca, 1992), TRACR3D (Travis, 1984), and MAGNUM-2D (England et al., 1985).

\section{Computer Requirements:}

The PORFLOW code is written in standard FORTRAN-77 and is easy to install on most mainframe computer systems. The code has been installed on a Cray XMP/24. The code is relatively easy to convert to different computer systems. However, practical applications of the PORFLOW code to realistic, flow and transport problems in multidimensions require the availability of a scientific workstation or mainframe computer. The simulations presented in this report were performed on a Cray X/MP supercomputer. 
The PORFLOW, version 2.3 computer code was originally developed for the U.S. Department of Energy and is therefore in the public domain. All versions of the PORFLOW code, however, are copyright protected. Copies of the source code are available from Analytic and Computational Research, Inc., Los Angeles, California.

\section{Code References:}

Baca, R. G., "A Finite Element Computer Code for Variably-Saturated Flow in Fractured-Porous Media," (in preparation), EG\&G Idaho, Inc., Idaho Falls, ID (1992).

Runchal, A. K. and B. Sagar, "PORFLOW: A Model for Fluid Flow, Heat, and Mass Transfort in Multifluid, Multiphase Fractured or Porous Media: User's Manual Version 2.30," Analytic and Computational Research, Inc., Los Angeles, CA (1990).

Runchal, A. K., B. Sagar, R. G. Baca, and N. W. Kline, "PORFLO - A Continuum Model for Fluid Flow, Heat Transfer, and Mass Transport in Porous Media: Model Theory, Numerical Methods, and Computational Tests," RHO-CR-150 P, Rockwell Hanford Operations, Richland, WA (1985).

\section{FLOWMC}

\section{Description:}

The FLOWMC computer code was developed at EG\&G Idaho for specific application to the waste migration problems at the INEL. It has also been applied to locations at the Nevada Test Site (Magnuson et al., 1991). The code is capable of solving vertical one-dimensional unsaturated flow through a multilayered system. The numerical solution of the flow equation uses a one-dimensional Galerkin finite element technique. The travel time through the vadose zone is calculated from the resulting pressure head and moisture content profiles.

The stochastic FLOWMC code accounts for the statistical nature and spatial variability of hydraulic properties through the use of probability distribution functions. A set of correlated random fields are generated and used in a Monte Carlo simulation process. For each random field, the code solves the one-dimensional flow equation and the water travel-time equation. The Monte Carlo process is performed until the statistical properties (i.e., mean, median and variance) of the travel-time distribution converge. 
The FLOWMC code computes the distribution of water travel-times as a function of the following input data:

o statistical distribution of the net surface water flux

o statistical distribution of any or all hydrologic parameters

o spatial correlation of hydraulic conductivity.

The code also has the capability to stochastically model dissolved phase transport in one-dimension. The transport component of the code is designed to solve the time-dependent advection-disperion equation numerically or analytically. The analytical solution (Eslinger and Sagar, 1988) is for a simplified form of the transport equation and uses weighted averages for the transport coefficients.

\section{Computer Requirements:}

The FLOWMC code is written in standard FORTRAN-77 and is easy to install on most mainframe computer systems. The code has been installed on DEC and SUN workstation and PCs with 386 or 486 processors. However, practical applications of the code require the availability of a high performance workstation or mainframe computer.

Code References:

Nguyen, H. D., S. O. Magnuson and R. G. Baca, "Probabilistic Model for Flow and Transport in Porous Media," (In preparation), EG\&G Idaho, Inc., Idaho Falls, ID.

Magnuson, S. O, S. J. Maheras, H. D. Nguyen, A. S. Rood, J. I. Sipos, M. J. Case, M. A.

Mcl _enzie-Carter, "Radiological Performance Assessment for the Area 5 Radioactive

Waste Management Site at the Nevada Test Site," Draft, EG\&G Idaho, Inc., Idaho Falls, ID (1991).

Eslinger, P. W., and B. Sagar, EPASTAT: A Computer Model for Estimating Releases at the Accessible Environment Boundary of a High-Level Nuclear Waste Repository Mathematical Model and Numerical Model, SD-BWI-TA-022, Hanford, Washington (1988). 


\section{General References}

Baca, R. G., "Configuration Management and Software Control Procedure for Subsurface Flow and Transport Simulation Codes," EGG-WM-9103, EG\&G Idaho, Inc., Idaho Falls, ID (1990).

Celia, M. A., E. T. Bouloutas and R. L. Zarba, "A General Mass-Conservative Numerical Solution for the Unsaturated Flow Equation," Water Resources Research, Vol. 26, No. 7, pp. 1483-1496 (1991).

Celia, M. A., "The Princeton One-Dimensional Unsaturated Code," Princeton University, Princeton, NJ (1991).

Celia, M. A., "The Princeton Two-Dimensional Unsaturated Code," Princeton University, Princeton, NJ (1991).

England, R. L., N. W. Kline, K. J. Ekblad, and R. G. Baca, MAGNUM-2D Computer Code: Users Guide, RHO-BW-CR-143, Rockwell International, Richland, WA (1985).

Huyakorn, P. S., J. B. Kool and J. B. Robertson, "VAM2D - Variably Saturated Analysis Model in Two-Dimensions," NUREG/CR-5352, U. S. Nuclear Regulatory Commission, Washington, DC (1989

Pruess, K., "TOUGH User's Guide," LBL-20700, NUREG/CR-4645, prepared for the U. S. Nuclear Regulatory Commission by Lawrence Berkeley Laboratory, Berkeley, CA (1987).

Travis, B. J., "TRACR3D: A Model of Flow and Transport in Porous-Fractured Media," LA-9667-MS, Los Alamos National Laboratory, Los Alamos, NM (1984).

Voss, C. I., "A Finite-Element Simulation Model for Saturated-Unsaturated, Fluid-Density-Dependent Ground-Water Flow with Energy Transport or Chemically-Reactive Single-Species Solute Transport," U. S. Geological Survey, Reston, VA (1984).

Yeh, G. T. and D. S. Ward, "FEMWATER: A Finite-Element Model of Water Flow Through Saturated-Unsaturated Porous Media," ORNL-5567, Oak Ridge National Laboratory, Oak Ridge, TN (1979). 


\section{APPENDIX II - HYDRAULIC DATA FOR MONTE CARLO SIMULATIONS}

The RWMC stratigraphy consists of an interbedded sequence of basalt flows, sedimentary interbeds and surficial sediments. Statistical descriptions of the hydraulic properties were required for the Monte Carlo simulations of vadose zone travel time. This statistical description, as used in this study, was limited to the hydraulic conductivity of each of the different material types.

The probabilistic description for the surficial sediments and sedimentary interbeds was taken from Lee (1990). The permeability data for the sediments revealed a randomness that could best be approximated by the Weibull distribution which takes the form

$$
p d f_{\text {Weibull }}=b \frac{x^{b-1}}{a^{b}} \exp \left[-\left(\frac{x}{a}\right)^{b}\right]
$$

where $a$ and $b$ are fitted parameters. The values for $a$ and $b$ for the sedimentary materials are give in Table 1. The cumulative Weibull distribution function was used for generating permeability values for the surficial sediments and sedimentary interbeds.

Table 1. Weibull Distribution Parameters for Sedimentary Materials

$\begin{array}{ccc}\text { Material } & \mathrm{a} & \mathrm{b} \\ \text { Surficial Sediments } & 5.20 & 0.368 \\ \text { Interbed Sediments } & 21.17 & 0.256\end{array}$

(the resulting permeability is in milliDarcies)

The basalt flows may be categorized into three different flow groups corresponding to the top vesicular, massive, and bottom vesicular segments. Empirical distributions, based on 
the data collected in Lee (1990), were created from which permeabilities were generated for use in the Monte Carlo simulations. These empirical distributions for each material type are shown in Figure 1.

For completeness, the van Genuchten parameters that were used in the Monte Carlo simulations are given in Table 2. The sources for these parameters were given in Section 4.2 of this report.

Table 2. van Genuchten Parameters for Monte Carlo Simulations

\begin{tabular}{lllll}
\hline \multicolumn{1}{c}{ Material } & $\theta_{s}$ & $\theta_{r}$ & $\alpha\left(m^{-1}\right)$ & $n$ \\
Surficial Sediments & 0.48 & 0.1 & 1.216 & 1.36 \\
Interbed Sediments & 0.48 & 0.01 & 1.216 & 1.36 \\
Vesicular Basalt & 0.228 & 0.1 & 3.84 & 1.474 \\
Massive Basalt & 0.145 & 0.01 & 3.84 & 1.474 \\
\hline
\end{tabular}



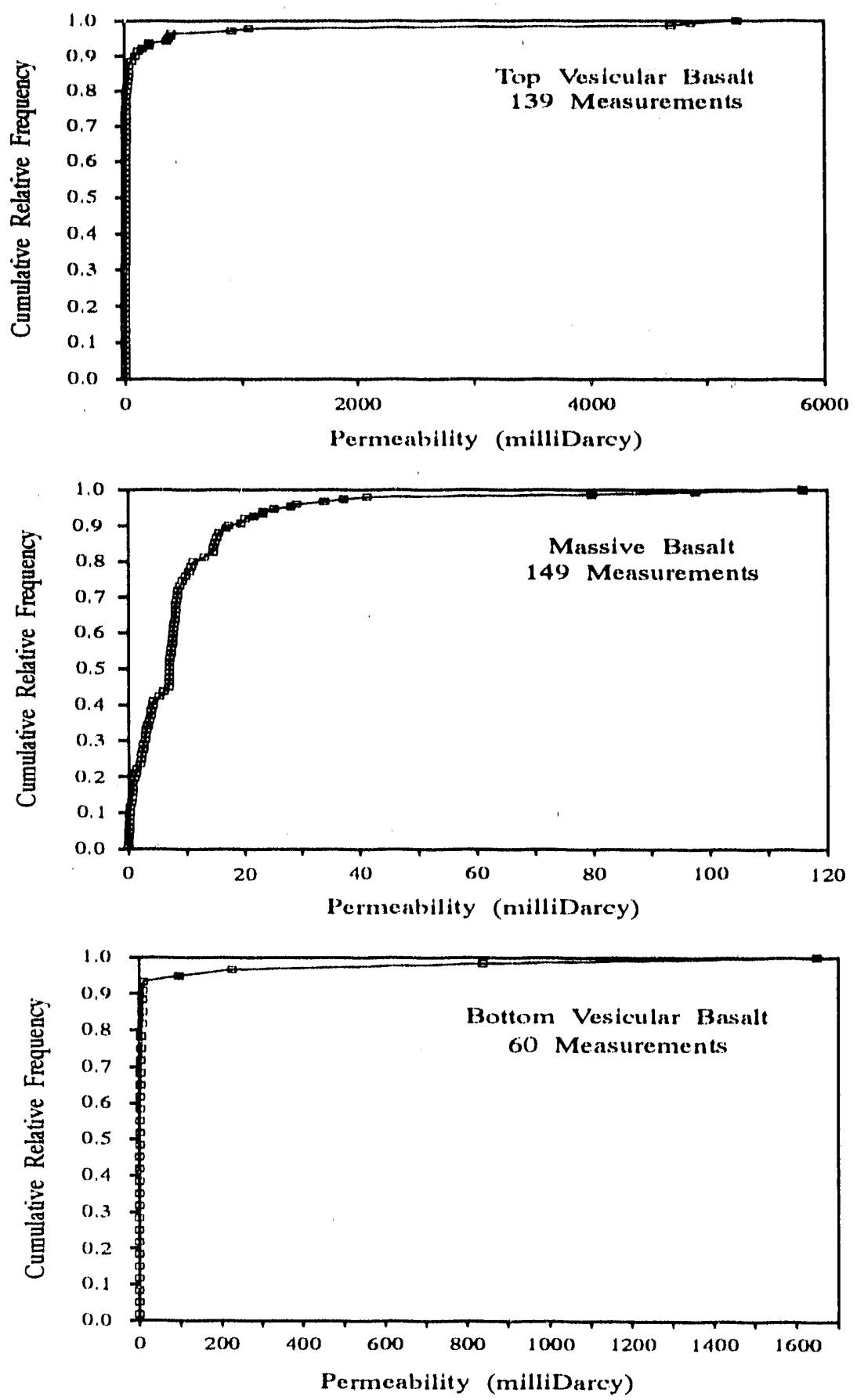

Figure 1. Empirical Cumulative Relative Frequency Distributions for Monte Carlo Simulations. 


\section{DISTRIBUTION LIST}

\section{OFFSITE}

D. J. Alexander

U. S. Department of Energy

Forrestal Bldg,, MS RW-23-2

Washington, DC 20585

W. Barrish

INEL Oversight Program

1410 N. Hilton

Boise, ID 83706

J. S. Baldwin

Martin Marietta

Central Waste Management

Oak Ridge, TN 37831

\section{A. J. Baker}

Engineering Science and Mechanics

University of Tennessee

Knoxville, TN 37996-2030

A. K. Bhattacharyya

Department of Environmental Resources

Bureau of Radiation Protection

P. O. Box 2063

Harrisburg, PA 17120

K. H. Birdsell

Los Alamos National Laboratory

P. O. Box 1663

Los Alamos, NM 87545

G. Bloomsburg

Agricultural Engineering Department

University of Idaho

Moscow, ID 83843

T. C. Chee

U.S. Department of Energy

Research and Management Division

DP-123, A237

Germantown, MD 20545
D. L. Chery, Jr.

U. S. Nuclear Regulatory Commission MS-4H3

Washington, DC 20555

J. N. Chung

Mechanical and Material Engineering

Washington State University

Pullman, WA 99164-2920

R. B. Codell

U. S. Nuclear Regulatory Commission MS-4H3

Washington, DC 20555

J. R. Cook

Westinghouse Savannah River Company

Savannah River Laboratory

P. O. Box 616, Bldg. 773-43A

Aiken, SC 29802

J. C. Corey

Westinghouse Savannah River Site

P. O. Box A

Aiken, SC 29808

M. Cunnane

Golder Associates, Inc.

4104 148th Avenue NE

Redmond, WA 98052

P. A. Davis

Sandia National Laboratories

Division 6416

P. O. Box 5800

Albuquerque, NM 87185

P. Dickman

U. S. Department of Energy

Waste Management Project Office

P. O. Box 14100)

Las Vegas, NV 89114 
M. R. Dolenc

Reynolds Electrical and Engineering Co. P. O. Box 98521

Las Vegas, NV 89193-8521

F. H. Dove

IT Corporation

5301 Central Ave, N.E., Sulte 700

Albuquerque, NM 87108

R. R. Eaton

Sandia National Laboratories

Fluid Mechanics and Heat Transfer Div.

Albuquerque, NM 87185

M. Ebra

Westinghouse Savannah River Company Environmental Restoration Program

P. O. Box 616

Aiken, SC $298(12$

L. Ebeling

Reynolds Electrical and Engineering Co.

P. O. Box 98521

Las Vegas, NV 89193-8521

A. I. El-Kadi

Holcomb Research Institute

Colorado State University

Fort Collins, CO 80521

C. G. Enfield

U. S. Environmental Protection Agency

Robert S. Kerr Environmental Lab

P. O. Box 1198

Ada, OK 74820

M. J. Fayer

Pacific Northwest Laboratory

P. O. Box 999, MS K6-77

Richland, WA 99352

J. I. Finnie

Civil Engineering Department

University of Idaho

Moscow, ID 83843
R. A. Freeze:

Department of Geological Sclencess

University of Britisli Columbia

Vancouver, BC V6T 2B4, Canada

G. W. Gee

Pacific Northwest Laboratory

P. O. Box 999, MS K6-77

Richland, WA 99352

T. C. Gunderson

Los Alamos National Laboratory

P. O. Box 1663, MS K491

Los Alamos, NM 87545

D. Hillel

Dept, of Plant and Soll Science

University of Massachusets

12A Stockbridge Hall

Amherst, MA ()1003

C. Y. Hung

U. S. Environmental Protection Agency

Office of Radiation Programs, ANR-460

401 M Street, S. W.

Washington, DC 20460)

V. Ichimura

Chem-Nuclear Systems

P. O. Box 726

Barnwell, SC 29182

B. Izadi

Agricultural Engineering

University of Idaho

Moscow, ID 83843

T. L. Jones

Department of Agronomy

and Horticulture

New Mexico State University

Las Cruces, NM 880(03-(0)(03

W. A. Jury

Department of Soils

University of California

at Riverside

Riverside, CA 90(024 
C. T. Klnouid

Pacific Northwest Laboratory

P. O. Box 999, MS K6-77

Rlchland, WA 99352

K. Kersch

SAIC, Inc.

101 Convention Center Drive

Sulte 407

Las Vegas, NV 89109

C. P. Llou

Civil Engineering Department

University of Idaho

Moscow, ID 8384.3

J. T. McCord

Sandia National Laboratories

Division 6416

Albuquerque, NM 85185-5800)

L. M. McDowell-Boyer

Oak Ridge National Laboratory

Grand Junction Office

Grand Junction, CO $815(12$

C. McLane

ENVIRON Int. Corp.

4350 N. Fairfax Dr., Sulte 30)(

Arlington, VA $222(13$

D. B. McLaughlin

Department of Civil Engineering

Massachusetts Institute of Technology

Room 48.329

Cambridge, MA (02139

\section{S. A. Mizell}

Desert Research Institute

P. O. Box 60220

Reno, NV 89506

S. P. Neuman

Dept, of Hydrology and Water Resources

University of Arizona

Tucson, AZ 85721
W. Newberry

U, S. Department of Energy

Nuclear Energy LLW Management

Program, NE-24

Washington, DC 20545

T', J, Nlcholson

U. S. Nuclear Regulatory Commission

Division of Englneering Safety

MS NL-()()5

Washington, DC 20555

J. W. Nyhan

Los Alamos National Laboratory

P. O. Box 1663

Los Alamos, NM 8754.5

U. S. Park

Sclence Applications International Corp.

101 Convention Center Drive

Las Vegas, NV 89109

F. L. Parker

4400 Iroquols

Nashville, TN 3720.5

D. M. Peterson

INTERA Associates

810() Mountain Road NE, Sulte 213

Albuquerque, NM 87110

O. A. Plumb

Mechanleal and Material Engineering

Washington State University

Pullman, WA 99164-2920

J. Pope

Westinghouse Savannah River Company

Environmental Restoration Program

P. O. Box 616

Alken, SC $298(12$

R. W. Prindle

Sandia National Laboratories

Division 6312

P. O. Box 5800)

Albuquerque, NM 87185 
'T, C, Rasmussen

Dept. of Hydrology and Water Resources University of Arizona

Tucson, AZ 85721

M. L. Rockhold

Pacific Northwest Laboratory

P. O. Box 999, MS K6.77

Richland, WA 99352

\section{C. Rogers}

Rogers \& Assoclates Engineering Corp.

P. O. Box 330

Salt Lake City, UT 84110

A. K. Runchal

ACR, Inc.

3106 Inglewood $B \mid v d$.

Los Angeles, CA 90066

B. Sagar

Center for Nuclear Waste Repository

Analyses

Southwest Research Institute

6220) Culebra Rd.

P. O. Drawer 28510

San Antonio, TX 78284

S. G. Schmelling

U. S. Environmental Protection Agency

Robert S. Kerr Environmental Lab

P. O. Box 1198

Ada, OK 74820

M. Silberberg

U. S. Nuclear Regulatory Commission

Office Nuclear Regulatory Research

Washington, DC 20555

J. L. Smoot

Pacific Northwest Laboratory

P. O. Box 999, MS K6-77

Richland, WA 99352

R. J, Starmer

ERM-Program Management Corp

7926 Jones Branch Drive, Suite 210

McLean, VA 22102
B. Stevens

75 Toponce Dr.

Pocatello, ID 83204

C. J. Suen

Brookhaven Natlonal Laboratory

Nuclear Waste and Materials

Technology Division

Upton, Long Island, NY 11973

Technical Library

Los Alamos National Laboratory

P. O. Box 1663

Los Alamos, NM 87545

Technical Library

Oak Ridge National Laboratory

P. O, Box X

Oak Ridge, TN 37830

Technical Library

Savannah River Laboratory

P. O. Box 1663

Los Alamos, NM 87545

B. J. Travis

Los Alamos National Laboratory

P. O. Box 1663

Los Alamos, NM 87545

S. W. Tyler

Water Resources Center

Desert Research Institute

P. O. Box 60220

Reno, NV 89506-(1220)

B. L. Roberts

EG\&G Rocky Flats, Inc.

P. O. Box 464

Golden, CO 80402-()464

M. T. van Genuchten

USDA-ARS, U.S. Salinity Laboratory

4500 Glenwood Drive

Riverside, CA 92.501 
P. van der Heljde

Holcomb Research Instltute

Colorado State University

Fort Collins, CO 8(1521

A. W. Warrick

Unlversity of Arizona

Dept, of Soll and Water Sclence

Tucson, AZ 85721

\section{E. P. Weeks}

U. S. Geological Survey

Federal Center, MS 413

Denver, CO 80225

M. Weinstein

U. S. Nuclear Regulatory Commission MS NL/S-260)

Washington, DC 201555

\section{P. J. Wierenga}

University of Arizona

Dept. of Soll and Water Science

Tucson, AZ 85721

D. C. Wiggert

Michigan State University

A120 Engineering Research Complex

East Lansing, Michigan 48824

\section{J. L. Wilson}

New Mexico Institute of Mining and Technology

Dept. of Geosclences

Socorro, NM 87801

Westinghouse Hanford Company

P. O. Box 1970)

Richland, WA 99352

J. D. Davis, MS H4-.54

R. Khaleel, MS H4-54

J. C. Sonnichsen, MS H4-54

A. $\mathrm{Yu}$

Westinghouse Savannah River Company

Savannah River Laboratory

P. O. Box 616

Aiken, SC 298012

\section{ONSITE}

DOE ID

M. C. Bennett

L. A. Green

EG\&G Idaho Inc.

R, C, Arnett

R, G. Baca

C. W. Bishop

L. C. Hull

J. M. Hubbell

J. F. Keck

C. B. Lee

J. A. Logan

S. O. Magnuson

S. J. Maheras

R. C. Martineau

J. G. McCarthy

J. W. McConnell

R. L. Nitschke

H. D. Nguyen

I. Porro

A. S. Rond

A. L. Schafer-Perini

R. R, Seitz

J. B. Sisson

C. S. Smith

A. J. Sondrup

L. V. Street

M. E. Sussman

J. C. Walton

T, R. Wood

INEL Technical Library

Westinghouse Idaho Nuclear Co. Inc.

T. R. Thomas

E. C. Thiel

\section{U.S. Geological Survey}

J. R. Pittman

L. J. Mann 

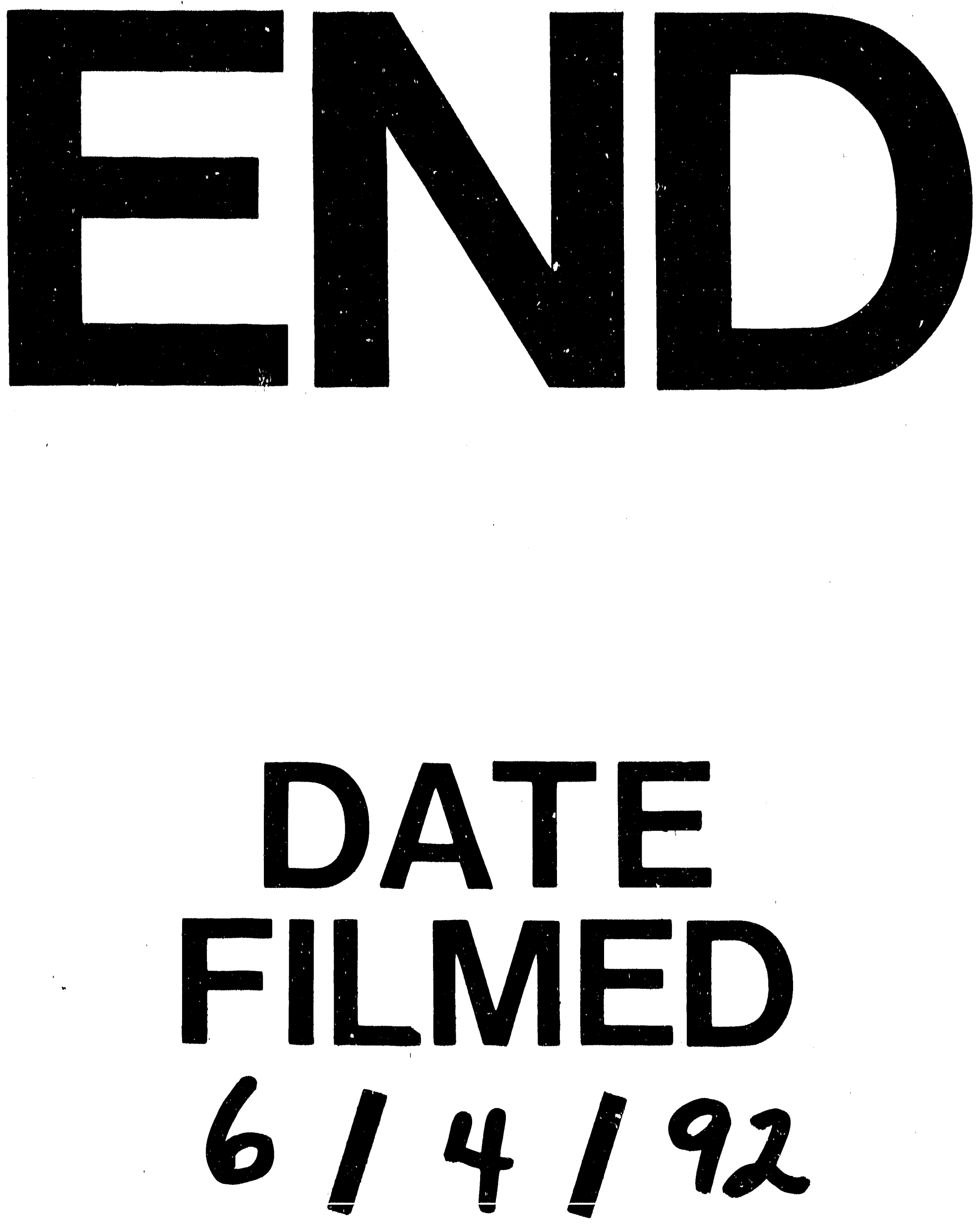

1 